\title{
25. Problemfelder und Indikatoren im Bereich der Gentechnologien: eine Synopse
}

\subsection{Einführung: Motivation und Zielsetzung}

Die IAG Gentechnologiebericht der Berlin-Brandenburgischen Akademie der Wissenschaften hat als Langzeit-Monitoring-Projekt die Aufgabe, neue Entwicklungen und Tendenzen der Gentechnologien zu beobachten und einer breiten Öffentlichkeit zugänglich zu machen. Zu diesem Zweck werden Analysen der wissenschaftlichen Entwicklungen durchgeführt, Veranstaltungen für die Öffentlichkeit angeboten (fachwissenschaftliche und allgemeinverständliche Vorträge, Workshops, Fortbildungen für Lehrende, Schulvorträge) sowie in regelmäßigen Abständen Publikationen (Stellungnahmen, Themenbände, Broschüren und die umfassenden und namengebenden Gentechnologieberichte) veröffentlicht. All diese Formate und Maßnahmen sollen nicht nur unterschiedlichsten Zielgruppen gut verständliche Informationen liefern, sondern auch einen wohlinformierten Diskurs über zum Teil gesellschaftlich kontrovers diskutierte Themen auf dem Gebiet der Gentechnologien fördern.

Ein Alleinstellungsmerkmal der Arbeit der IAG ist die sogenannte Problemfelderhebung und Indikatorenanalyse (siehe auch Hucho, Kap. 2). ${ }^{1}$ Im Zentrum steht hierbei, das vielschichtige und von den verschiedensten Fachdisziplinen geprägte Feld der Gentechnologien in Deutschland in einer messbaren und repräsentativen Form für die fachliche und interessierte breite Öffentlichkeit zu erschließen (Diekämper/Hümpel, 2015: 16). Im Rahmen dieses Ansatzes werden den qualitativ erhobenen Problemfeldern Indikatoren (quantitative Daten im Zeitverlauf) zugeordnet. Angewendet wurde dieses Vorgehen sowohl im Rahmen der thematisch breit aufgestellten Gentechnologiebe-

1 Da die Problemfeld- und Indikatorenanalyse eine zentrale Methode der IAG Gentechnologiebericht darstellt, sind einführende und allgemeine Überlegungen sowie Ausführungen zu diesem Vorgehen im Wortlaut ähnlich bereits in vorherigen Veröffentlichungen der IAG beschrieben (siehe etwa: Osterheider et al., 2020; Osterheider et al., 2019; Marx-Stölting/Könniger, 2018; Marx-Stölting, 2017; Diekämper/Hümpel, 2012). 
richte $(2005,2009,2015,2018$ und 2021) als auch in den Themenbänden, die ausführlich Entwicklungen zu spezifischen Themen beleuchten und reflektieren. Bereits im vierten Gentechnologiebericht wurde ein modifiziertes Vorgehen bei der Problemfeld- und Indikatorenanalyse durchgeführt (Marx-Stölting/Könniger, 2018); dieses wird nun in dem vorliegenden fünften Gentechnologiebericht fortgeführt.

\subsection{Problemfelderhebung und Indikatorenanalyse im Bereich der Gentechnologien}

\subsubsection{Vorgehen}

Das Ziel der Problemfelderhebung ist, Themen und Fragestellungen zu benennen und zu bündeln, die in der Öffentlichkeit, vor allem in der Medienberichterstattung, eine Rolle spielen. Zunächst wird nun das in den Themenbänden übliche Vorgehen der Problemfelderhebung und der Indikatorenanalyse beschrieben; danach werden die Modifikationen beschrieben, die im vierten und nun auch im fünften Gentechnologiebericht erfolgten. ${ }^{2}$

Üblicherweise werden im Rahmen der gewählten Methodik mehrere Schritte durchgeführt: nach einer explorativen Recherche in Online-Suchmaschinen mit jeweils thematisch einschlägigen Suchbegriffen ${ }^{3}$ wird eine qualitative Analyse der Medienberichterstattung (Print und online) durchgeführt. ${ }^{4}$ Basierend auf deren Auswertung werden zu den jeweiligen Themen entsprechende Problemfelder ermittelt. Problemfelder sind definiert als Themen oder Fragestellungen, die von der Öffentlichkeit wahrgenommen werden können. Im Anschluss werden die Problemfelder quantitativ gewichtet und innerhalb der vier etablierten Leitdimensionen angeordnet: wissenschaftliche, ethische, soziale sowie

2 Ein besonderer Dank gilt Dr. Sabine Könninger, die dieses modifizierte Vorgehen gemeinsam mit Dr. Lilian Marx-Stölting im Rahmen des vierten Gentechnologieberichts entwickelt und umgesetzt hat (Marx-Stölting/Könninger, 2018: 279-297).

3 Sowohl im Rahmen der qualitativen Inhaltsanalyse als auch bei der später beschriebenen Indikatorenerhebung ist jedoch zu beachten, dass die Verwendung eines Suchbegriffs für ein Thema auch immer das Risiko birgt, nicht alle relevanten Quellen zu finden.

4 Die Methodik wurde im Laufe der Zeit immer weiter optimiert; seit 2011 dient ein umfangreicher Textkorpus als Grundlage für eine qualitative Auswertung. Neben der Recherche mit den jeweils thematisch einschlägigen Suchbegriffen in den Online-Archiven der vier Leitmedien Die Zeit (www.zeit. de), Der Spiegel (www.spiegel.de) sowie der FAZ (www.faz.net/archiv) und der SZ (www.sueddeutsche.de) wurde eine explorative Suche in Online-Suchmaschinen durchgeführt (2011-2017 in Google, ab 2017 zusätzlich in Metager). In den Jahren 2006 bis 2012 wurden Expert*innenbefragungen durchgeführt und darauf basierend die Problemfelder entwickelt. 
ökonomische Dimension. ${ }^{5}$ Daran anschließend werden Indikatoren (quantitative Daten) diesen Problemfeldern zugeordnet. Definiert werden Indikatoren als belegbare empirische Daten oder Größen, die Auskunft über Sachverhalte geben, die selbst nicht direkt ermittelbar sind (vgl. Domasch/Boysen, 2007: 18). Beispiele für Problemfelder sind u. a. der Forschungsstandort Deutschland, die Realisierung von Forschungszielen, die öffentliche Wahrnehmung oder auch die Patentierung wissenschaftlicher Ergebnisse (eine Übersicht der Problemfelder ist zu finden in Abb. 1). Indikatoren, die den Forschungsstandort Deutschland ausleuchten, sind z. B. die Höhe der öffentlichen Fördermittel, die Anzahl geförderter Projekte oder auch die Anzahl der Patentanmeldungen im Zeitverlauf.

Im vorliegenden fünften Bericht wurde an das Vorgehen im vierten Bericht angeknüpft: Die Themen, die zum Teil seit Beginn der Arbeit im Rahmen von Themenbänden - einige auch mehrmals - behandelt wurden, stehen im Fokus der folgenden modifizierten Problemfeldanalyse. Dies sind die Themen: Gentherapie, Grüne Gentechnologie, Gendiagnostik, Stammzellforschung, Epigenetik, synthetische Biologie und Organoidforschung (als Unterbereich der Stammzellforschung). Mit der gleichen Methodik wurden auch ausgewählte Indikatoren für die genannten Themen erhoben. Dies ermöglicht im Rahmen der Auswertung der Indikatoren auch einen Vergleich der Themenbereiche miteinander.

Es wurde eine Zusammenschau aller von der IAG seit Beginn ihrer Arbeit eruierten Problemfelder erstellt (Abb. 1). Hierfür wurden sämtliche erhobene Problemfelder miteinander verglichen. In Tabelle 1 werden die Problemfelder, zugeordnet zu den vier Leitdimensionen, ausführlich erläutert und diesen jeweils relevante Indikatoren wie auch Beiträge aus dem fünften Bericht zugeordnet. Ein Unterschied zu der sonst üblichen Problemfelderhebung besteht darin, dass die Problemfelder nicht inhaltlich gewichtet wurden, sondern visualisiert wird, in welchem Umfang sich die Problemfelder hinsichtlich der verschiedenen Themenbereiche überschneiden. Die Problemfelder wurden zudem zum Teil zusammengefasst: so umfasst z. B. das Problemfeld Status Entität sowohl den Status des Organoids als auch des Embryos. Diese Zusammenfassungen werden in Tabelle 1 erläutert. Eine ausführliche Beschreibung der Methode ist zu finden in Marx-Stölting/Könninger (2018: 280-283).

5 Bei der Darstellung im Bereich der Grünen Gentechnologie wurde - zwischen 2007 und 2009 - anstatt der ethischen die ökologische Dimension angeführt. 
Abbildung 1: Problemfelder im Bereich der Gentechnologien in Deutschland: eine Zusammenschau ${ }^{6}$

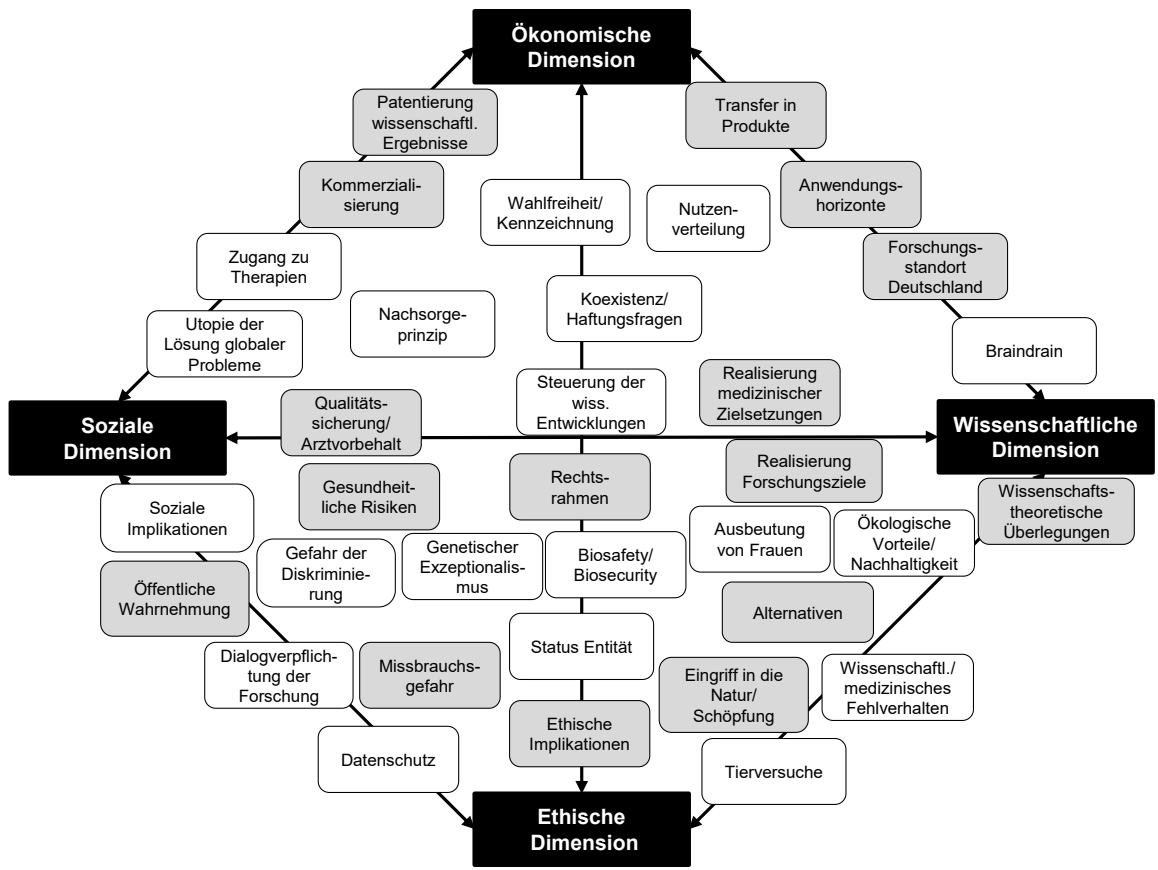

Die Abbildung basiert auf einer themenübergreifenden Analyse aller früheren Problemfelddarstellungen der IAG zu den Themen Epigenetik, Stammzellforschung, Gentherapie, Gendiagnostik, synthetische Biologie, Grüne Gentechnologie und Organoide. Sich inhaltlich überschneidende Problemfelder, die unterschiedlich benannt waren, wurden dabei zusammengefasst. Helle Blasen sind Problemfelder, die insbesondere für ein oder zwei Themen relevant sind, graue Problemfelder betreffen mindestens drei oder mehr Themen. Die inhaltliche Füllung der einzelnen Problemfelder sowie deren Relevanz für verschiedene Themenbereiche entnehmen Sie bitte der Tabelle 1.

Quellen: Wobus et al. (2006), Schmidtke et al. (2007), Müller-Röber et al. (2007), Hucho et al. (2008), Müller-Röber et al. (2009), Fehse/Domasch (2011), Köchy/Hümpel (2012), Müller-Röber et al. (2013), Müller-Röber et al. (2015), Walter/ Hümpel (2017), Zenke et al. (2018), Bartfeld et al. (2020).

\subsection{Problemfelder und Indikatoren zu ihrer Beschreibung}

Die Problemfelder werden nun vorgestellt und inhaltlich detailliert beschrieben. Zudem werden den Feldern ausgewählte Indikatoren zugeordnet und es wird auf relevante Kapitel des vorliegenden Themenbandes verwiesen: Auf diese Weise wird neben der quantitativen Ausleuchtung der Problemfelder auch ermöglicht, anhand der Vorstellungen und

6 Die Abbildung basiert auf der Problemfeldarstellung aus dem vierten Gentechnologiebericht (Marx-Stölting/Könninger, 2018: 285 ff.) und wurde ergänzt sowie zum Teil geändert; deshalb gibt es Überschneidungen im Inhalt. 
Reflexionen in den Kapiteln mehr über die Problemfelder zu erfahren. Die Reihenfolge der Problemfelder orientiert sich an den genannten etablierten vier Leitdimensionen.

Tabelle 1: Problemfelder der Gentechnologien in Deutschland und Indikatoren zu ihrer Beschreibung ${ }^{7}$

\begin{tabular}{|c|c|c|}
\hline Problemfeld & Beschreibung & Indikatoren/Beiträge \\
\hline \multicolumn{3}{|c|}{ Im Kreuzfeld aller Dimensionen } \\
\hline Rechtsrahmen & $\begin{array}{l}\text { Der rechtliche Rahmen auf nationaler, europäischer und } \\
\text { internationaler Ebene bestimmt über die Zulässigkeit von } \\
\text { gentechnischen Verfahren und definiert ihren Einsatz } \\
\text { in der wissenschaftlichen Praxis bzw. formuliert dafür } \\
\text { notwendige Rahmenbedingungen. Er hat eine Funktion } \\
\text { bei der Vermittlung von einander widersprechenden } \\
\text { Interessen und Schutzgütern. Der Rechtsrahmen wird in } \\
\text { jedem der sieben Themenfelder diskutiert. }\end{array}$ & $\begin{array}{l}\text { Beiträge: } \\
\text { Fehse et al. (Kap. 9) } \\
\text { Taupitz (Kap. 15) } \\
\text { Molnár-Gábor/Merk (Kap. 16) } \\
\text { van den Daele/Broer (Kap. 21) } \\
\text { Dederer (Kap. 22) }\end{array}$ \\
\hline $\begin{array}{l}\text { Steuerung wis- } \\
\text { senschaftlicher } \\
\text { Entwicklungen }\end{array}$ & $\begin{array}{l}\text { Das Problemfeld umfasst die Steuerung und Rahmenbe- } \\
\text { dingungen medizinisch-wissenschaftlicher Entwicklungen } \\
\text { jenseits der Steuerung durch Gesetze (siehe Problemfeld } \\
\text { Rechtsrahmen), wie bspw. die Steuerung durch öffentliche } \\
\text { Registrierungsinstanzen, Fachbegutachtungen von } \\
\text { Forschungsvorhaben, Ethikkommissionen oder Moratorien. } \\
\text { Diskutiert werden die Vielfalt der Möglichkeiten der Steue- } \\
\text { rung und auch die Fragen nach den (Un-)Möglichkeiten und } \\
\text { Schwierigkeiten der Steuerung medizinisch-wissenschaftli- } \\
\text { cher Entwicklungen. Dieses Problemfeld wurde } 2017 \text { für die } \\
\text { Stammzellforschung neu hinzugefügt; auch im angeglieder- } \\
\text { ten Bereich der Organoidforschung spielt es eine Rolle. }\end{array}$ & $\begin{array}{l}\text { Beiträge: } \\
\text { Leßmöllmann (Kap. 14) } \\
\text { Taupitz (Kap. 15) } \\
\text { Molnár-Gábor/Merk (Kap. 16) } \\
\text { Schicktanz/Buhr (Kap. 18) } \\
\text { Fangerau/Labisch (Kap. 20) } \\
\text { van den Daele/Broer (Kap. 21) } \\
\text { Dederer (Kap. 22) } \\
\text { Renn (Kap. 23) }\end{array}$ \\
\hline \multicolumn{3}{|c|}{ Wissenschaftliche Dimension <> Ethische Dimension } \\
\hline Alternativen & $\begin{array}{l}\text { In verschiedenen Bereichen werden als weniger proble- } \\
\text { matisch angesehene Alternativen thematisiert. Meist geht } \\
\text { es dabei um Ansätze, die ohne Gentechnik auskommen. } \\
\text { So werden im Bereich der Grünen Gentechnik z. B. der } \\
\text { Biolandbau oder auch soziale Projekte zur Bekämpfung } \\
\text { des Hungers in der Welt als gentechnikfreie Alternativen } \\
\text { diskutiert. Bei der Gentherapie werden z. B. herkömmliche } \\
\text { Medikamente als Alternativen zur als riskant wahrgenom- } \\
\text { menen somatischen Gentherapie gesehen. }\end{array}$ & $\begin{array}{l}\text { Beiträge: } \\
\text { Walter/Gasparoni (Kap. 3) } \\
\text { Renn (Kap. 23) }\end{array}$ \\
\hline
\end{tabular}

7 Kursiv geschriebene Ausdrücke in der Tabelle geben Bezeichnungen von Problemfeldern der Einzelthemen wieder, die inhaltlich in dem jeweiligen Problemfeld aufgehen und daher nicht mehr als gesondertes Problemfeld aufgelistet wurden. Dies ist zum einen darauf zurückzuführen, dass die Themenfelder für verschiedene Bereiche zum Teil unterschiedlich benannt oder auch im Laufe der Zeit umbenannt wurden. Zum anderen wurden für den vorliegenden Bericht verschiedene Themenfelder für eine bessere Lesbarkeit der umfangreichen Problemfeldtabelle zusammengefasst, wo inhaltlich möglich. 


\begin{tabular}{|c|c|c|}
\hline Problemfeld & Beschreibung & Indikatoren/Beiträge \\
\hline & $\begin{array}{l}\text { Besonders prominent ist die Diskussion um Alternativen im } \\
\text { Bereich der Stammzellforschung bezogen auf die Nutzung } \\
\text { von humanen embryonalen Stammzellen (hES-Zellen). Hier } \\
\text { wird nicht die Nutzung von Gentechnik an sich, sondern } \\
\text { die Gewinnung von hES-Zellen aus Embryonen in vitro, } \\
\text { die dabei zerstört werden, als problematisch angesehen. } \\
\text { Daher werden alternative Stammzellen wie humane adulte } \\
\text { Stammzellen, humane induzierte pluripotente Stammzellen } \\
\text { (hiPS-Zellen) und humane parthenogenetische }{ }^{8} \text { Stamm- } \\
\text { zellen diskutiert, deren Gewinnung als ethisch vertretbarer } \\
\text { angesehen wird bzw. deren Nutzung auch rechtlich zulässig } \\
\text { ist. Im Kontext der Stammzellforschung thematisiert } \\
\text { das Problemfeld die Qualität, Gesundheitsrisiken und } \\
\text { Wirtschaftlichkeit von Ansätzen, die auf hES-Zell-Linien } \\
\text { basieren, im Vergleich zu alternativen Methoden. Auch im } \\
\text { Bereich der Organoidforschung spielen Alternativen eine } \\
\text { Rolle: hES-Zell-Linien werden in der Organoidforschung } \\
\text { z. B. eingesetzt, um Embryoide herzustellen (als Ersatz für } \\
\text { Embryonen). }\end{array}$ & \\
\hline $\begin{array}{l}\text { Wissen- } \\
\text { schaftliches/ } \\
\text { medizinisches } \\
\text { Fehlverhalten }\end{array}$ & $\begin{array}{l}\text { In den letzten Jahren gab es immer wieder Skandale, } \\
\text { ausgelöst durch wissenschaftliches Fehlverhalten im } \\
\text { Sinne der Veröffentlichung nicht reproduzierbarer oder } \\
\text { gefälschter Daten oder der Überschreitung ethischer } \\
\text { Grenzen, so etwa im Bereich der Stammzellforschung. } \\
\text { Auch im Kontext experimenteller Therapien (z. B. } \\
\text { Gentherapien) wird von Verstößen gegen das ärztliche } \\
\text { Berufsrecht oder den medizinischen Ethos berichtet. }\end{array}$ & \\
\hline Tierversuche & $\begin{array}{l}\text { Zu diesem Problemfeld zählt die Frage der Notwendigkeit } \\
\text { von bzw. möglicher Alternativen zu Tierversuchen in der } \\
\text { Forschung und ihrer Aussagekraft für bzw. Übertrag- } \\
\text { barkeit auf den Menschen, ebenso wie die Themati- } \\
\text { sierung des Tierschutzgesetzes, insbesondere bei der } \\
\text { Stammzellforschung und der Organoidforschung. }\end{array}$ & \\
\hline
\end{tabular}

8 Stammzellen, die aus Embryonen gewonnen werden, die durch das sog. Verfahren der Parthenogenese aus einer nicht befruchteten Eizelle erzeugt wurden. 


\begin{tabular}{|c|c|c|}
\hline Problemfeld & Beschreibung & Indikatoren/Beiträge \\
\hline $\begin{array}{l}\text { Ausbeutung von } \\
\text { Frauen }\end{array}$ & $\begin{array}{l}\text { Dieses Problemfeld wurde nur } 2006 \text { im Kontext der } \\
\text { Stammzellforschung angeführt. Das Problemfeld betrach- } \\
\text { tet einen kritischen Aspekt der Stammzellforschung, der } \\
\text { mit der Gewinnung von Zellmaterial, insbesondere von } \\
\text { Eizellen (im Kontext des sogenannten therapeutischen } \\
\text { Klonens), zusammenhängt. Die Gewinnung von Eizellen } \\
\text { erfordert eine Hormonbehandlung, die mit gesundheitli- } \\
\text { chen Risiken verbunden ist. Diese Risiken könnten Frauen } \\
\text { aus Entwicklungsländern oder wirtschaftlich schlecht ge- } \\
\text { stellte Frauen, gegen finanzielle Leistungen, eher in Kauf } \\
\text { nehmen als wohlhabende Frauen aus Industrienationen. }\end{array}$ & \\
\hline $\begin{array}{l}\text { Ökologische } \\
\text { Vorteile/Nach- } \\
\text { haltigkeit }\end{array}$ & $\begin{array}{l}\text { Das Problemfeld spielt besonders im Bereich der Grünen } \\
\text { Gentechnologie eine wichtige Rolle (komplementär zu } \\
\text { den angenommenen ökologischen Risiken). Sowohl } \\
\text { Befürworter*innen als auch Gegner*innen des Einsatzes } \\
\text { von Gentechnik in der Landwirtschaft argumentieren, } \\
\text { dass ihre Herangehensweise mit ökologischen Vorteilen } \\
\text { verbunden und nachhaltig ist. So wollen zahlreiche } \\
\text { Befürworter*innen etwa durch insektenresistente } \\
\text { Nutzpflanzen den Einsatz von Insektiziden reduzieren. } \\
\text { Viele Gegner*innen hingegen argumentieren gegen } \\
\text { die industrielle Landwirtschaft, die sie durch die Grüne } \\
\text { Gentechnologie befördert sehen und für umweltschädlich } \\
\text { halten, und setzen etwa auf den Biolandbau. Die Frage, } \\
\text { ob gentechnisch veränderte Pflanzen ökologische Vor- } \\
\text { teile bringen oder nicht, ist nach wie vor umstritten. }\end{array}$ & $\begin{array}{l}\text { Beiträge: } \\
\text { Clemens (Kap. 7) } \\
\text { Renn (Kap. 23) }\end{array}$ \\
\hline $\begin{array}{l}\text { Wissenschafts- } \\
\text { theoretische } \\
\text { Überlegungen }\end{array}$ & $\begin{array}{l}\text { Es werden allgemeine Voraussetzungen, Methoden und } \\
\text { Ziele von Wissenschaft und ihrer Form der Erkenntnis- } \\
\text { gewinnung hinterfragt. Wissenschaftstheoretische Über- } \\
\text { legungen umfassen etwa die Lebensdefinition im Bereich } \\
\text { der synthetischen Biologie, aber auch das Genkonzept, } \\
\text { das der Gendiagnostik und Gentherapie zugrunde liegt. }\end{array}$ & $\begin{array}{l}\text { Beiträge: } \\
\text { Rheinberger/Müller-Wille } \\
\text { (Kap. 11) } \\
\text { Jawaid/Mansuy (Kap. 12) } \\
\text { Alex/Winkler (Kap. 13) } \\
\text { Winkler/Prainsack (Kap. 17) } \\
\text { Schicktanz/Buhr (Kap. 18) } \\
\text { Fangerau/Labisch (Kap. 20) }\end{array}$ \\
\hline $\begin{array}{l}\text { Eingriff in die } \\
\text { Natur/ } \\
\text { Schöpfung }\end{array}$ & $\begin{array}{l}\text { Insbesondere im Bereich der Grünen Gentechnologie } \\
\text { und synthetischen Biologie werden ethische und theo- } \\
\text { logische Aspekte sowie Naturvorstellungen diskutiert. } \\
\text { Insbesondere das Überspringen von Artgrenzen kann als } \\
\text { ein massiver Eingriff in die Natur bzw. (religiös formuliert) } \\
\text { Schöpfung gesehen werden. Bei der Grünen Gentech- } \\
\text { nologie könnten z. B. gewisse Grenzen überschritten } \\
\text { werden, die von manchen als ethisch relevant betrachtet } \\
\text { werden, bspw. beim Einsatz von Tier- und Humangenen }\end{array}$ & $\begin{array}{l}\text { Beiträge: } \\
\text { Alex/Winkler (Kap. 13) } \\
\text { Fangerau/Labisch (Kap. 20) } \\
\text { Hampel et al. (Kap. 24) }\end{array}$ \\
\hline
\end{tabular}




\begin{tabular}{|c|c|c|}
\hline Problemfeld & Beschreibung & Indikatoren/Beiträge \\
\hline & $\begin{array}{l}\text { in Pflanzen oder bei der synthetischen Biologie, wenn es } \\
\text { etwa um die Herstellung völlig neuartiger Stoffwechsel- } \\
\text { wege geht, die in der Natur nicht vorkommen. Ein } \\
\text { Beispiel im Bereich der Forschung mit Organoiden ist die } \\
\text { Herstellung von Mensch-Tier-Chimären. Des Weiteren } \\
\text { wird wie auch allgemein in der Stammzellforschung } \\
\text { diskutiert, ob z. B. bei der Herstellung von sogenannten } \\
\text { Embryoiden ethische Grenzen überschritten werden. } \\
\text { Dabei spielen unterschiedlichen Wertungen von Natür- } \\
\text { lichkeit eine Rolle. }\end{array}$ & \\
\hline \multicolumn{3}{|c|}{ Wissenschaftliche Dimension <> Soziale Dimension } \\
\hline $\begin{array}{l}\text { Realisierung } \\
\text { Forschungsziele }\end{array}$ & $\begin{array}{l}\text { Wissenschaftliche Forschung will neue Erkenntnisse } \\
\text { gewinnen, um z. B. neue Technologien zu entwickeln. } \\
\text { Zu ihrem Wesen gehört dabei eine begrenzte Planbarkeit } \\
\text { und Ergebnisoffenheit. Gleichwohl beeinflussen die vor- } \\
\text { handenen Rahmenbedingungen - wie die wissenschaft- } \\
\text { liche Infrastruktur, Fördermöglichkeiten und geltendes } \\
\text { Recht - die Realisierung von gesetzten Forschungszielen, } \\
\text { die sich quantifizierbar z. B. in Veröffentlichungen, } \\
\text { Forschungspreisen oder akademischen Abschlüssen } \\
\text { niederschlagen. Die Realisierung von Forschungszielen ist } \\
\text { für alle Themen zentral. }\end{array}$ & $\begin{array}{l}\text { Indikatoren: } \\
\text { Anzahl internationaler Fach- } \\
\text { artikel zu den Themenfeldern } \\
\text { der IAG (5B-04) } \\
\text { Förderung durch den Bund zu den } \\
\text { Themenfeldern der IAG (5B-05) } \\
\text { Fördermaßnahmen der DFG } \\
\text { zu den Themenfeldern der IAG } \\
\text { (5B-07) } \\
\text { EU-Fördermaßnahmen mit } \\
\text { ausgewiesener deutscher } \\
\text { Beteiligung zu den Themen- } \\
\text { feldern der IAG (5B-08) } \\
\text { Beiträge: } \\
\text { Walter/Gasparoni (Kap. 3) } \\
\text { Mundlos (Kap. 4) } \\
\text { Zenke/Bartfeld (Kap. 5) } \\
\text { Fehse (Kap. 6) } \\
\text { Clemens (Kap. 7) } \\
\text { Erb (Kap. 8) } \\
\text { Fehse et al. (Kap. 9) } \\
\text { Jawaid/Mansuy (Kap. 12) } \\
\text { Korte (Kap. 19) } \\
\text { van den Daele/Broer (Kap. 21) } \\
\text { Renn (Kap. 23) }\end{array}$ \\
\hline $\begin{array}{l}\text { Realisierung } \\
\text { medizinischer } \\
\text { Zielsetzungen }\end{array}$ & $\begin{array}{l}\text { Das Ziel medizinischer Humanforschung ist, neue Erkennt- } \\
\text { nisse zu gewinnen, um Erkrankungen und Gesundheits- } \\
\text { risiken (besser) vorzubeugen, zu diagnostizieren, zu lindern } \\
\text { oder zu heilen: Dies macht den besonders sensiblen Charak- } \\
\text { ter biomedizinischer Forschung aus. Probleme ergeben sich } \\
\text { dann, wenn nicht alle medizinischen Zielsetzungen umsetz- } \\
\text { bar sind, weil sie sich als schwieriger, zeitraubender oder } \\
\text { kostenintensiver, rechtlich schwerer umsetzbar herausstellen } \\
\text { als zunächst angenommen. Die Realisierung medizinischer } \\
\text { Zielsetzungen ist für alle Themen relevant, steht jedoch bei } \\
\text { der Grünen Gentechnologie nicht im Vordergrund. }\end{array}$ & $\begin{array}{l}\text { Beiträge: } \\
\text { Walter/Gasparoni (Kap. 3) } \\
\text { Mundlos (Kap. 4) } \\
\text { Zenke/Bartfeld (Kap. 5) } \\
\text { Fehse (Kap. 6) } \\
\text { Fehse et al. (Kap. 9) } \\
\text { Jawaid/Mansuy (Kap. 12) } \\
\text { Winkler/Prainsack (Kap. 17) } \\
\text { Schicktanz/Buhr (Kap. 18) } \\
\text { Korte (Kap. 19) }\end{array}$ \\
\hline
\end{tabular}




\begin{tabular}{|c|c|c|}
\hline Problemfeld & Beschreibung & Indikatoren/Beiträge \\
\hline \multicolumn{3}{|c|}{ Wissenschaftliche Dimension <> Ökonomische Dimension } \\
\hline $\begin{array}{l}\text { Anwendungs- } \\
\text { horizonte }\end{array}$ & $\begin{array}{l}\text { Anwendungshorizonte werden für alle Themen diskutiert. } \\
\text { Sie schließen visionäre Ziele mit hohem Innovations- } \\
\text { potenzial ein, deren Durchführbarkeit entsprechend } \\
\text { ungewiss ist. Für die Stammzellforschung sind patienten- } \\
\text { spezifische Stammzelltherapien ein Beispiel; für die Grüne } \\
\text { Gentechnologie etwa trockenresistente Nutzpflanzen. } \\
\text { Die somatische Gentherapie mittels Genomchirurgie ist } \\
\text { derzeit zum Teil noch ebenso unsicher wie der breite } \\
\text { Einsatz der Pharmakogenetik im Bereich der Gendia- } \\
\text { gnostik, wobei in beiden Gebieten erste klinische Erfolge } \\
\text { zu verzeichnen sind. Bei der synthetischen Biologie wäre } \\
\text { ein Beispiel die Entwicklung von Mikroorganismen, die } \\
\text { Umweltverschmutzungen beheben könnten. Auch epi- } \\
\text { genetische Modifikationen gehören zu den Anwendungs- } \\
\text { horizonten der Gentechnik. Für die Organoidforschung } \\
\text { sind patientenspezifische Therapien oder auch der } \\
\text { Organersatz potenzielle Beispiele. }\end{array}$ & $\begin{array}{l}\text { Beiträge: } \\
\text { Alle Beiträge }\end{array}$ \\
\hline Braindrain & $\begin{array}{l}\text { In einer dynamischen globalisierten Forschungsland- } \\
\text { schaft mit entsprechenden Mobilitätsanforderungen } \\
\text { läuft Deutschland Gefahr, wissenschaftliche Talente zu } \\
\text { verlieren, ohne dass im vergleichbaren Maß Wissen- } \\
\text { schaftler*innen gewonnen werden können. Für den } \\
\text { in Deutschland umstrittenen Bereich der Stammzell- } \\
\text { forschung bedeutete dies etwa gerade anfangs, dass } \\
\text { hochqualifizierte Wissenschaftler*innen aus beruflichen, } \\
\text { politischen, wirtschaftlichen oder auch rechtlichen } \\
\text { Gründen (Restriktionen durch das Stammzell- und } \\
\text { Embryonenschutzgesetz) das Land verließen. Damit geht } \\
\text { im globalen Standortwettbewerb und Forschungswett- } \\
\text { lauf wichtiges Know-how verloren und ökonomisches } \\
\text { Potenzial bleibt ungenutzt. Dasselbe Phänomen spielt } \\
\text { heute auch noch bei der Grünen Gentechnik eine wich- } \\
\text { tige Rolle, da aufgrund der politischen Situation etwa } \\
\text { Freilandversuche mit gentechnisch veränderten Pflanzen } \\
\text { in Deutschland nicht mehr durchführbar sind. }\end{array}$ & $\begin{array}{l}\text { Beitrag: } \\
\text { van den Daele/Broer (Kap. 21) }\end{array}$ \\
\hline
\end{tabular}




\begin{tabular}{|c|c|c|}
\hline Problemfeld & Beschreibung & Indikatoren/Beiträge \\
\hline $\begin{array}{l}\text { Forschungs- } \\
\text { standort } \\
\text { Deutschland }\end{array}$ & $\begin{array}{l}\text { Für ein an Rohstoffen armes Land wie Deutschland ist } \\
\text { eine wissensbasierte Ökonomie von zentraler Bedeutung } \\
\text { für die wirtschaftliche Prosperität und den gesellschaft- } \\
\text { lichen Wohlstand. Die internationale Attraktivität eines } \\
\text { Forschungsstandortes hängt von einer Vielzahl an Fakto- } \\
\text { ren ab, z. B. der vorhandenen wissenschaftlichen Infra- } \\
\text { struktur, dem Ausmaß und der Art an Fördermaßnahmen } \\
\text { oder auch von nationalen rechtlichen Regelungen, die die } \\
\text { wissenschaftliche Praxis beeinflussen. Der internationale } \\
\text { Ruf und die Vernetzung innerhalb der globalisierten } \\
\text { Forschungslandschaft spielen ebenfalls eine Rolle. Das } \\
\text { Problemfeld beinhaltet Themen wie Forschungsförderung } \\
\text { in Deutschland, Publikationsleistungen deutscher For- } \\
\text { scher*innen und rechtliche Rahmung. Auf den Gebieten } \\
\text { der Stammzellforschung und der Organoidforschung } \\
\text { (insbesondere bei Verwendung von hES-Zellen) oder } \\
\text { der Grünen Gentechnologie wird aufgrund rechtlicher } \\
\text { Beschränkungen eine mögliche Abkopplung von der } \\
\text { internationalen Forschung problematisiert. }\end{array}$ & $\begin{array}{l}\text { Indikatoren: } \\
\text { Neuerscheinungen zu den } \\
\text { Themenfeldern der IAG (5B-02) } \\
\text { Anzahl internationaler Fach- } \\
\text { artikel zu den Themenfeldern } \\
\text { der IAG (5B-04) } \\
\text { Förderung durch den Bund zu } \\
\text { den Themenfeldern der IAG } \\
\text { (5B-05) } \\
\text { Fördermaßnahmen der DFG } \\
\text { zu den Themenfeldern der IAG } \\
\text { (5B-07) } \\
\text { EU-Fördermaßnahmen mit } \\
\text { ausgewiesener deutscher } \\
\text { Beteiligung zu den Themen- } \\
\text { feldern der IAG (5B-08) } \\
\text { Beiträge: } \\
\text { van den Daele/Broer (Kap. 21) } \\
\text { Osterheider et al. (Kap. 26) }\end{array}$ \\
\hline $\begin{array}{l}\text { Nutzen- } \\
\text { verteilung }\end{array}$ & $\begin{array}{l}\text { Besonders im Kontext der Grünen Gentechnologie stellt } \\
\text { sich die Frage, wie der etwaige Nutzen der Technologie } \\
\text { verteilt wird. Dazu gehört bspw. die Frage, ob es für die } \\
\text { Verbraucher*innen einen Nutzen gibt oder ob dieser z. B. } \\
\text { auf den Bereich der landwirtschaftlichen Erzeuger*innen } \\
\text { beschränkt bleibt. Leistet die Grüne Gentechnologie } \\
\text { einen Beitrag zur gesunden Ernährung? Auch Fragen } \\
\text { nach globaler Gerechtigkeit werden in diesem Kontext } \\
\text { diskutiert, d. h. ob ein Nutzen sich nur auf bestimmte, } \\
\text { z. B. europäische Länder beschränkt oder sich auch auf } \\
\text { Entwicklungsländer bezieht. }\end{array}$ & $\begin{array}{l}\text { Beiträge: } \\
\text { Kolleck/Sauter (Kap. 10) } \\
\text { Jawaid/Mansuy (Kap. 12) } \\
\text { Renn (Kap. 23) }\end{array}$ \\
\hline $\begin{array}{l}\text { Transfer in } \\
\text { Produkte }\end{array}$ & $\begin{array}{l}\text { Wissenschaft kann auch unter ökonomischen Prämissen } \\
\text { bewertet werden (hier sind auch die Entwicklungen an } \\
\text { Universitäten/Forschungseinrichtungen und in der Wirt- } \\
\text { schaft zu unterscheiden). Das ist vor allem dann möglich, } \\
\text { wenn konkrete Produkte zur Marktreife geführt werden. } \\
\text { Zu nennen wären hier etwa der Einsatz gendiagnosti- } \\
\text { scher Verfahren in der Medizin, insektenresistente und } \\
\text { herbizidtolerante Pflanzen bei der Grünen Gentechno- } \\
\text { logie, erste gentherapeutische Medikamente auf dem } \\
\text { Markt sowie Stammzelltherapien basierend auf hES- } \\
\text { oder hiPS-Zellen. Nicht in allen Wissenschaftsgebieten } \\
\text { werden Forschungsergebnisse gleichermaßen effizient } \\
\text { in neue Produkte überführt. Gleichzeitig führt der Druck } \\
\text { zur ökonomischen Verwertung von Forschungsergeb- } \\
\text { nissen gegebenenfalls zu verfrühten, nicht haltbaren } \\
\text { Versprechungen. }\end{array}$ & $\begin{array}{l}\text { Beiträge: } \\
\text { Mundlos (Kap. 4) } \\
\text { Fehse (Kap. 6) } \\
\text { Clemens (Kap. 7) } \\
\text { Erb (Kap. 8) } \\
\text { Fehse et al. (Kap. 9) } \\
\text { Kolleck/Sauter (Kap. 10) } \\
\text { Korte (Kap. 19) } \\
\text { van den Daele/Broer (Kap. 21) } \\
\text { Dederer (Kap. 22) } \\
\text { Renn (Kap. 23) }\end{array}$ \\
\hline
\end{tabular}




\begin{tabular}{|c|c|c|}
\hline Problemfeld & Beschreibung & Indikatoren/Beiträge \\
\hline \multicolumn{3}{|c|}{ Ethische Dimension <> Soziale Dimension } \\
\hline $\begin{array}{l}\text { Öffentliche } \\
\text { Wahrnehmung }\end{array}$ & $\begin{array}{l}\text { Der Einsatz und die Etablierung neuer technologischer } \\
\text { Verfahren hängen zentral von deren gesellschaftlicher } \\
\text { Wahrnehmung ab. Das öffentliche Interesse an der The- } \\
\text { matik zeigt sich bspw. anhand der Präsenz der Themen in } \\
\text { den Print-/Onlinemedien, der Veröffentlichung populär- } \\
\text { wissenschaftlicher Publikationen sowie der Quantität } \\
\text { öffentlicher Veranstaltungen. Die beständige Information } \\
\text { und Teilhabe der Menschen an aktuellen Entwicklungen } \\
\text { der Forschung ist idealerweise ein selbstverständlicher } \\
\text { Bestandteil gesamtgesellschaftlicher Aushandlungs- } \\
\text { prozesse; sie hat auch Auswirkungen auf die öffentliche } \\
\text { Bewertung/Akzeptanz einer Technologie. }\end{array}$ & $\begin{array}{l}\text { Indikatoren: } \\
\text { Mediale Abbildung der } \\
\text { Themenfelder der IAG (5B-01) } \\
\text { Neuerscheinungen zu den } \\
\text { Themenfeldern der IAG (5B-02) } \\
\text { Online-Suchanfragen zu den } \\
\text { Themenfeldern der IAG (5B-03) } \\
\text { Öffentliche Veranstaltungen } \\
\text { zu den Themenfeldern der IAG } \\
\text { (5B-06) } \\
\text { Beiträge: } \\
\text { Alex/Winkler (Kap. 13) } \\
\text { Leßmöllman (Kap. 14) } \\
\text { Renn (Kap. 23) } \\
\text { Hampel et al. (Kap. 24) } \\
\text { Osterheider et al. (Kap. 26) }\end{array}$ \\
\hline $\begin{array}{l}\text { Soziale } \\
\text { Implikationen }\end{array}$ & $\begin{array}{l}\text { Forschung und Entwicklung werfen Fragen nach ihren } \\
\text { gesellschaftlichen Implikationen auf. Häufig können diese } \\
\text { Implikationen im Frühstadium der Forschung noch nicht } \\
\text { identifiziert werden, weil z. B. Forschungsziele noch vage } \\
\text { sind. Mögliche Implikationen werden meist erst absehbar } \\
\text { oder sichtbar, wenn eine bestimmte Forschung schon } \\
\text { etabliert ist. Dann kann die Gefahr bestehen, dass ihre } \\
\text { Etablierung nicht mehr änderbar ist. In der Diskussion } \\
\text { um Stammzellforschung werden z. B. im Kontext der } \\
\text { Herstellung von Eizellen aus Stammzellen - bisher im } \\
\text { Tierversuch erprobt - mögliche Implikationen für Mensch } \\
\text { und Gesellschaft abgeleitet. Dabei werden Fragen nach } \\
\text { Veränderungen von Sexualität, Zeugung und Fortpflan- } \\
\text { zung sowie dem konventionellen Familienmodell auf- } \\
\text { geworfen. Die epigenetische Forschung, um ein weiteres } \\
\text { Beispiel zu nennen, stiftet neue Handlungsräume in } \\
\text { Bezug auf gesundheitliche Vorsorge. Diese Vorsorge } \\
\text { kann sich zum einen auf das Individuum beziehen, zum } \\
\text { anderen werden auch intergenerationelle epigenetische } \\
\text { Effekte diskutiert. Die Epigenetik geht dabei über die } \\
\text { klassische Genetik insofern hinaus, als dass sie Umwelt- } \\
\text { einflüsse und Lebensgewohnheiten als ursächlich für eine } \\
\text { spezifische Disposition ansieht. Vor diesem Hintergrund } \\
\text { könnte sich möglicherweise zukünftig auch gesellschafts- } \\
\text { politischer Regelungsbedarf einstellen, etwa zum Schutz } \\
\text { vor Diskriminierung. }\end{array}$ & $\begin{array}{l}\text { Indikatoren: } \\
\text { Mediale Abbildung der } \\
\text { Themenfelder der IAG (5B-01) } \\
\text { Neuerscheinungen zu den } \\
\text { Themenfeldern der IAG (5B-02) } \\
\text { Online-Suchanfragen zu den } \\
\text { Themenfeldern der IAG (5B-03) } \\
\text { Öffentliche Veranstaltungen } \\
\text { zu den Themenfeldern der IAG } \\
\text { (5B-06) } \\
\text { Beiträge: } \\
\text { Fehse et al. (Kap. 9) } \\
\text { Jawaid/Mansuy (Kap. 12) } \\
\text { Alex/Winkler (Kap. 13) } \\
\text { Winkler/Prainsack (Kap. 17) } \\
\text { Schicktanz/Buhr (Kap. 18) } \\
\text { Fangerau/Labisch (Kap. 20) } \\
\text { Renn (Kap. 23) }\end{array}$ \\
\hline
\end{tabular}




\begin{tabular}{|c|c|c|}
\hline Problemfeld & Beschreibung & Indikatoren/Beiträge \\
\hline $\begin{array}{l}\text { Gesundheitliche } \\
\text { Risiken }\end{array}$ & $\begin{array}{l}\text { Mit gentechnischen Verfahren können gesundheitliche } \\
\text { Risiken verbunden sein. So wird im Bereich der Gen- } \\
\text { therapie und der Transplantation von Stammzellen über } \\
\text { Nebenwirkungen wie etwa Leukämie diskutiert. Auch die } \\
\text { Grüne Gentechnik steht immer wieder unter Verdacht, } \\
\text { gesundheitliche Risiken zu bergen, obwohl zahlreiche } \\
\text { naturwissenschaftliche Studien dies nicht bestätigen } \\
\text { konnten. Im Bereich der Epigenetik wird umgekehrt } \\
\text { insbesondere in den populären Medien eine mögliche } \\
\text { Eigenverantwortung für gesundheitliche Risiken disku- } \\
\text { tiert. Hierbei wird ein Verantwortungsbegriff ins Zentrum } \\
\text { gestellt, der sich durch die aktuelle wissenschaftliche } \\
\text { Datenlage zur Epigenetik nicht untermauern lässt, aber } \\
\text { dennoch das Individuum in die Pflicht nehmen könnte, } \\
\text { Lebens- und Ernährungsgewohnheiten umzustellen - } \\
\text { bezogen nicht nur auf die eigene Gesundheit, sondern } \\
\text { auch auf die zukünftiger Kinder. }\end{array}$ & $\begin{array}{l}\text { Indikatoren: } \\
\text { Mediale Abbildung der } \\
\text { Themenfelder der IAG (5B-01) } \\
\text { Online-Suchanfragen zu den } \\
\text { Themenfeldern der IAG (5B-03) } \\
\text { Beiträge: } \\
\text { Walter/Gasparoni (Kap. 3) } \\
\text { Fehse et al. (Kap. 9) } \\
\text { Jawaid/Mansuy (Kap. 12) } \\
\text { Alex/Winkler (Kap. 13) }\end{array}$ \\
\hline Datenschutz & $\begin{array}{l}\text { Die Aufbewahrung von Biomaterial, z. B. im Bereich der } \\
\text { Organoidforschung und der Stammzellforschung, sowie } \\
\text { die Erhebung und Speicherung genetischer Daten, z. B. } \\
\text { im Bereich der Gendiagnostik, ermöglicht prinzipiell eine } \\
\text { weitergehende Nutzung, die individuelle Rechte tangie- } \\
\text { ren kann. Außerdem lassen genetische Informationen } \\
\text { oft Rückschlüsse auf die genetische Konstitution von } \\
\text { Familienangehörigen zu. In diesem Zusammenhang wird } \\
\text { sowohl das Recht auf informationelle Selbstbestimmung } \\
\text { als auch ein „Recht auf Nichtwissen“ diskutiert. Im Be- } \\
\text { reich der Organoidforschung wird zudem ein spezifischer } \\
\text { Informed Consent als notwendig erachtet (in Bezug auf } \\
\text { hiPS-Zellen und gewebsspezifische Stammzellen), da eine } \\
\text { komplette Anonymisierung der Daten nicht möglich oder } \\
\text { erwünscht ist, um z. B. patientenspezifische Therapien } \\
\text { zu entwickeln. }\end{array}$ & $\begin{array}{l}\text { Beiträge: } \\
\text { Alex/Winkler (Kap. 13) } \\
\text { Taupitz (Kap. 15) } \\
\text { Molnár-Gábor/Merk (Kap. 16) } \\
\text { Winkler/Prainsack (Kap. 17) }\end{array}$ \\
\hline $\begin{array}{l}\text { Dialog- } \\
\text { verpflichtung } \\
\text { der Forschung }\end{array}$ & $\begin{array}{l}\text { Forscher*innen aus den verschiedenen Themenbereichen } \\
\text { sehen die Notwendigkeit für einen frühzeitigen wechsel- } \\
\text { seitigen Austausch mit der Gesellschaft und Politik } \\
\text { über ethische und gesellschaftliche Aspekte der neuen } \\
\text { Technologien. Der Ruf nach einem öffentlichen Dialog } \\
\text { wird besonders im Bereich der synthetischen Biologie } \\
\text { sowie aktuell beim Thema Genome-Editing laut. }\end{array}$ & $\begin{array}{l}\text { Indikator: } \\
\text { Öffentliche Veranstaltungen } \\
\text { zu den Themenfeldern der IAG } \\
\text { (5B-06) } \\
\text { Beiträge: } \\
\text { Fehse et al. (Kap. 9) } \\
\text { Leßmöllmann (Kap. 14) } \\
\text { Schicktanz/Buhr (Kap. 18) }\end{array}$ \\
\hline
\end{tabular}




\begin{tabular}{|c|c|c|}
\hline Problemfeld & Beschreibung & Indikatoren/Beiträge \\
\hline $\begin{array}{l}\text { Missbrauchs- } \\
\text { gefahr }\end{array}$ & $\begin{array}{l}\text { Das Problemfeld bezieht sich auf den möglichen Miss- } \\
\text { brauch oder auch die Instrumentalisierung von Bio- und } \\
\text { Gentechnologien im weiteren Sinne (im Unterschied zum } \\
\text { konkreten Missbrauch von Stoffen, siehe Biosecurity). } \\
\text { Die im Rahmen vor allem der Gendiagnostik erhobenen } \\
\text { Daten generieren ein spezifisches Wissen, das durch die } \\
\text { hohe Aussagekompetenz, z. B. in Bezug auf die Gesund- } \\
\text { heitsrisiken eines Individuums, einen sensiblen Umgang } \\
\text { verlangt. Dabei soll einer Gefahr der Diskriminierung von } \\
\text { Menschen mit bestimmten genetischen Konstitutionen, } \\
\text { etwa durch Arbeitgeber*innen oder Versicherungen, } \\
\text { entgegengewirkt werden. Bei der Epigenetik wird über } \\
\text { eine mögliche Instrumentalisierung wissenschaftlicher } \\
\text { Hypothesen diskutiert. Neue Technologien wie die Grüne } \\
\text { Gentechnologie könnten gegen das Wohl des Menschen } \\
\text { verwendet werden, so wird kritisiert dass etwa Groß- } \\
\text { konzerne versuchen könnten, über die Kontrolle des } \\
\text { Saatgutes Kontrolle über Bevölkerungen zu erlangen. }\end{array}$ & $\begin{array}{l}\text { Beiträge: } \\
\text { Fehse et al. (Kap. 9) } \\
\text { Alex/Winkler (Kap. 13) } \\
\text { Taupitz (Kap. 15) } \\
\text { Molnár-Gábor/Merk (Kap. 16) } \\
\text { Winkler/Prainsack (Kap. 17) }\end{array}$ \\
\hline $\begin{array}{l}\text { Genetischer } \\
\text { Exzeptionalismus }\end{array}$ & $\begin{array}{l}\text { Hierbei ist die Frage zentral, ob und wenn ja, in welchem } \\
\text { Sinne genetischen Daten im Vergleich zu anderen me- } \\
\text { dizinischen Daten ein Sonderstatus zukommt. Dies wird } \\
\text { besonders für den Bereich der Gendiagnostik diskutiert. }\end{array}$ & $\begin{array}{l}\text { Beitrag: } \\
\text { Alex/Winkler (Kap. 13) }\end{array}$ \\
\hline $\begin{array}{l}\text { Gefahr der } \\
\text { Diskriminierung }\end{array}$ & $\begin{array}{l}\text { Personen mit bestimmten genetischen Dispositionen } \\
\text { könnten gesellschaftlich diskriminiert werden, etwa im } \\
\text { Arbeits- und Versicherungsbereich (siehe auch Miss- } \\
\text { brauchsgefahr). Durch die Möglichkeiten der vorgeburt- } \\
\text { lichen Diagnostik können z. B. Aussagen über genetische } \\
\text { Dispositionen des Fötus getroffen werden. Auch hier } \\
\text { besteht die Gefahr der Wertung und Diskriminierung. } \\
\text { Auch im Bereich der Epigenetik wird darüber diskutiert, } \\
\text { ob Diskriminierungspotenzial bestehen könnte. }\end{array}$ & $\begin{array}{l}\text { Beiträge: } \\
\text { Fehse et al. (Kap. 9) } \\
\text { Alex/Winkler (Kap. 13) } \\
\text { Taupitz (Kap. 15) } \\
\text { Molnár-Gábor/Merk (Kap. 16) } \\
\text { Winkler/Prainsack (Kap. 17) }\end{array}$ \\
\hline
\end{tabular}

Ethische Dimension <> Ökomische Dimension

\begin{tabular}{|c|c|c|}
\hline $\begin{array}{l}\text { Ethische } \\
\text { Implikationen }\end{array}$ & $\begin{array}{l}\text { Forschung - vor allem in den Biowissenschaften und ver- } \\
\text { schärft im biomedizinischen Bereich - generiert Wissen } \\
\text { und Anwendungen, die eine Auseinandersetzung mit } \\
\text { etwaigen Konsequenzen für den Menschen, die Gesell- } \\
\text { schaft und die Umwelt verlangen. Dabei spielen soziale } \\
\text { oder rechtliche Aspekte ebenso eine Rolle wie ethische } \\
\text { Fragen, die es gesellschaftlich zu diskutieren gilt und } \\
\text { die u. U. politischen Handlungsbedarf nach sich ziehen. } \\
\text { Dieses Problemfeld erfasst dabei ethische Implikationen } \\
\text { im Allgemeinen, die nicht als einzelnes konkretes Pro- } \\
\text { blemfeld erfasst wurden. Im Zusammenhana mit der }\end{array}$ & $\begin{array}{l}\text { Indikatoren: } \\
\text { Mediale Abbildung der } \\
\text { Themenfelder der IAG (5B-01) } \\
\text { Neuerscheinungen zu den } \\
\text { Themenfeldern der IAG (5B-02) } \\
\text { Online-Suchanfragen zu den } \\
\text { Themenfeldern der IAG (5B-03) } \\
\text { Öffentliche Veranstaltungen } \\
\text { zu den Themenfeldern der IAG } \\
\text { (5B-06) }\end{array}$ \\
\hline
\end{tabular}




\begin{tabular}{|c|c|c|}
\hline Problemfeld & Beschreibung & Indikatoren/Beiträge \\
\hline & $\begin{array}{l}\text { Gendiagnostik wird z. B. über das Recht auf informatio- } \\
\text { nelle Selbstbestimmung sowie über das Recht auf Nicht- } \\
\text { wissen diskutiert; außerdem nimmt diese Einfluss auf die } \\
\text { menschliche Fortpflanzung. Das zeigte nicht zuletzt die } \\
\text { kontroverse Diskussion um die Reproduktionstechniken } \\
\text { Präimplantationsdiagnostik und Pränataldiagnostik. } \\
\text { Die Forschung am Menschen ist höchst problematisch und } \\
\text { unterliegt deshalb strengen Standards und Kontrollen. In- } \\
\text { nerhalb gentherapeutischer Forschung wird eine Vielzahl } \\
\text { von forschungsethischen Fragen relevant, da es sich hier } \\
\text { derzeit noch um eine sehr risikobehaftete Technik handelt, } \\
\text { mit teilweise irreversiblen Konsequenzen. Daneben wird } \\
\text { die Anwendung eines Gentransfers im nicht therapeuti- } \\
\text { schen Bereich (sogenanntes Enhancement) oder in der } \\
\text { menschlichen Keimbahn problematisiert. } \\
\text { In der synthetischen Biologie wird außerdem die Bedeu- } \\
\text { tung des Lebensbegriffs diskutiert. Dabei geht es um die } \\
\text { Frage, ob und unter welchen Voraussetzungen „Leben“ } \\
\text { im normativ folgenreichen Sinn zu schützen ist. } \\
\text { Diskussionswürdige Aspekte auf dem Feld der Organoid- } \\
\text { forschung ergeben sich u. a. im Bereich der Tierethik. Eine } \\
\text { zentrale Frage ist, ob sich die Anzahl von Tierversuchen } \\
\text { durch bspw. Toxizitätstests an Organoiden statt an Tieren } \\
\text { verringern lässt oder durch mehr Forschung und damit ver- } \\
\text { bundenem erhöhten Bedarf an Versuchstieren ansteigt. Da } \\
\text { bei der Herstellung von Organoiden auch hES-Zellen ver- } \\
\text { wendet werden, spielen ethischen Argumente eine Rolle, } \\
\text { die im Kontext der Stammzellforschung diskutiert werden. }\end{array}$ & $\begin{array}{l}\text { Beiträge: } \\
\text { Fehse et al. (Kap. 9) } \\
\text { Jawaid/Mansuy (Kap. 12) } \\
\text { Alex/Winkler (Kap. 13) } \\
\text { Winkler/Prainsack (Kap. 17) } \\
\text { Schicktanz/Buhr (Kap. 18) }\end{array}$ \\
\hline Status Entität & $\begin{array}{l}\text { Das Problemfeld ist insbesondere für den Bereich der } \\
\text { Stammzellforschung (Status Embryo) mit hES-Zellen } \\
\text { relevant. Für die Herstellung von hES-Zell-Linien werden } \\
\text { frühe menschliche Embryonen aus In-vitro-Fertilisationen } \\
\text { „verbraucht". Diese sind ohne Implantation in den Uterus } \\
\text { nicht lebensfähig. Umstritten ist, ab wann schutzwürdi- } \\
\text { ges menschliches Leben beginnt und nach welchen Kri- } \\
\text { terien es definiert wird. Von der Definition hängt ab, ob } \\
\text { und welche Embryonen zu Forschungszwecken genutzt } \\
\text { werden dürfen. Das deutsche Embryonenschutzgesetz } \\
\text { und das Stammzellgesetz verbieten die Gewinnung von } \\
\text { hES-Zellen, erlauben aber unter bestimmten Auflagen } \\
\text { den Import bestehender hES-Zell-Linien zu Forschungs- } \\
\text { zwecken. Auch im Bereich der Organoidforschung spielt } \\
\text { der Status eine Rolle (Status Organoid): Diskutiert werden } \\
\text { das ontologische Verständnis, die ethische Beurteilung } \\
\text { sowie der rechtliche Status von Organoiden. Fragen der } \\
\text { Personalität sowie des Bewusstseins werden zudem im } \\
\text { Zusammenhang mit der Forschung an Hirnorganoiden } \\
\text { sowie sogenannten Embryoiden diskutiert. }\end{array}$ & $\begin{array}{l}\text { Beiträge: } \\
\text { Fehse et al. (Kap. 9) } \\
\text { Taupitz (Kap. 15) }\end{array}$ \\
\hline
\end{tabular}




\begin{tabular}{|c|c|c|}
\hline Problemfeld & Beschreibung & Indikatoren/Beiträge \\
\hline $\begin{array}{l}\text { Koexistenz/ } \\
\text { Haftungsfragen }\end{array}$ & $\begin{array}{l}\text { Es wird im Bereich der Grünen Gentechnologie diskutiert, } \\
\text { inwieweit die Koexistenz, also das Nebeneinander von } \\
\text { gentechnisch veränderten Pflanzen und konventioneller } \\
\text { bzw. ökologischer Landwirtschaft, möglich ist. Es geht } \\
\text { um landwirtschaftliche Strukturen, also darum, wie und } \\
\text { unter welchen Bedingungen Landwirtschaft betrieben } \\
\text { wird. Auch bestehende landwirtschaftliche Strukturen } \\
\text { werden teilweise kritisiert. Hierbei spielen auch spezielle } \\
\text { Haftungsregelungen eine Rolle, etwa für den Fall der } \\
\text { Ausbreitung von gentechnisch veränderten Pflanzen in } \\
\text { benachbarte Felder. }\end{array}$ & $\begin{array}{l}\text { Beiträge: } \\
\text { Fehse et al. (Kap. 9) } \\
\text { Kolleck/Sauter (Kap. 10) } \\
\text { Dederer (Kap. 22) } \\
\text { Renn (Kap. 23) }\end{array}$ \\
\hline $\begin{array}{l}\text { Wahlfreiheit/ } \\
\text { Kennzeichnung }\end{array}$ & $\begin{array}{l}\text { Das Problemfeld ist vor allem im Bereich der Grünen } \\
\text { Gentechnik relevant. Die dem Grundsatz der Wahlfreiheit } \\
\text { folgende Kennzeichnung von gentechnisch veränderten } \\
\text { Lebensmitteln erlaubt Verbraucher*innen die freie } \\
\text { Entscheidung, sich für oder gegen die Gentechnik bei } \\
\text { Lebensmitteln zu entscheiden. }\end{array}$ & $\begin{array}{l}\text { Beiträge: } \\
\text { Fehse et al. (Kap. 9) } \\
\text { van den Daele/Broer (Kap. 21) } \\
\text { Dederer (Kap. 22) } \\
\text { Renn (Kap. 23) } \\
\text { Hampel et al. (Kap. 24) }\end{array}$ \\
\hline $\begin{array}{l}\text { Biosafety/ } \\
\text { Biosecurity }\end{array}$ & $\begin{array}{l}\text { Die beiden Begriffe werden im Deutschen unter dem } \\
\text { Begriff der Biosicherheit zusammengefasst und zielen auf } \\
\text { Sicherheitsstandards zur Vorbeugung einer unbeabsich- } \\
\text { tigten Gefährdung der Umwelt (Biosafety), z. B. durch } \\
\text { eine Freisetzung von Mikroorganismen oder Stoffen aus } \\
\text { Laboren, bzw. eines beabsichtigten Missbrauchs (Bio- } \\
\text { security), z. B. in terroristischer Absicht. Biosafety-Fragen } \\
\text { werden insbesondere bei der synthetischen Biologie } \\
\text { und Grünen Gentechnologie aufgeworfen (ökologische } \\
\text { Risiken). Ob und wenn ja, welche ökologischen Risiken } \\
\text { bestehen, ist dabei jedoch umstritten. }\end{array}$ & $\begin{array}{l}\text { Beiträge: } \\
\text { Kolleck/Sauter (Kap. 10) } \\
\text { Renn (Kap. 23) }\end{array}$ \\
\hline \multicolumn{3}{|c|}{ Soziale Dimension <> Ökonomische Dimension } \\
\hline $\begin{array}{l}\text { Zugang zu } \\
\text { Therapien }\end{array}$ & $\begin{array}{l}\text { Bei etabliertem und breitem Einsatz zelltherapeutischer } \\
\text { Anwendungen stellt sich die Frage nach der Kostenüber- } \\
\text { nahme durch die gesetzlichen Krankenkassen und der } \\
\text { Bezahlbarkeit von individuellen Gesundheitsleistungen. } \\
\text { Das Problemfeld steht für eine mögliche Entwicklung, bei } \\
\text { der Therapien als Teil einer kostenintensiven „Spitzen- } \\
\text { medizin“ nur einer Minderheit zur Verfügung stehen } \\
\text { („Zweiklassenmedizin“). Diese Fragen der Verteilungs- } \\
\text { gerechtigkeit werden im Bereich der Gentherapie und der } \\
\text { Organoidforschung diskutiert. }\end{array}$ & $\begin{array}{l}\text { Beiträge: } \\
\text { Fehse (Kap. 6) } \\
\text { Fehse et al. (Kap. 9) }\end{array}$ \\
\hline
\end{tabular}




\begin{tabular}{|c|c|c|}
\hline Problemfeld & Beschreibung & Indikatoren/Beiträge \\
\hline $\begin{array}{l}\text { Kommerzia- } \\
\text { lisierung }\end{array}$ & 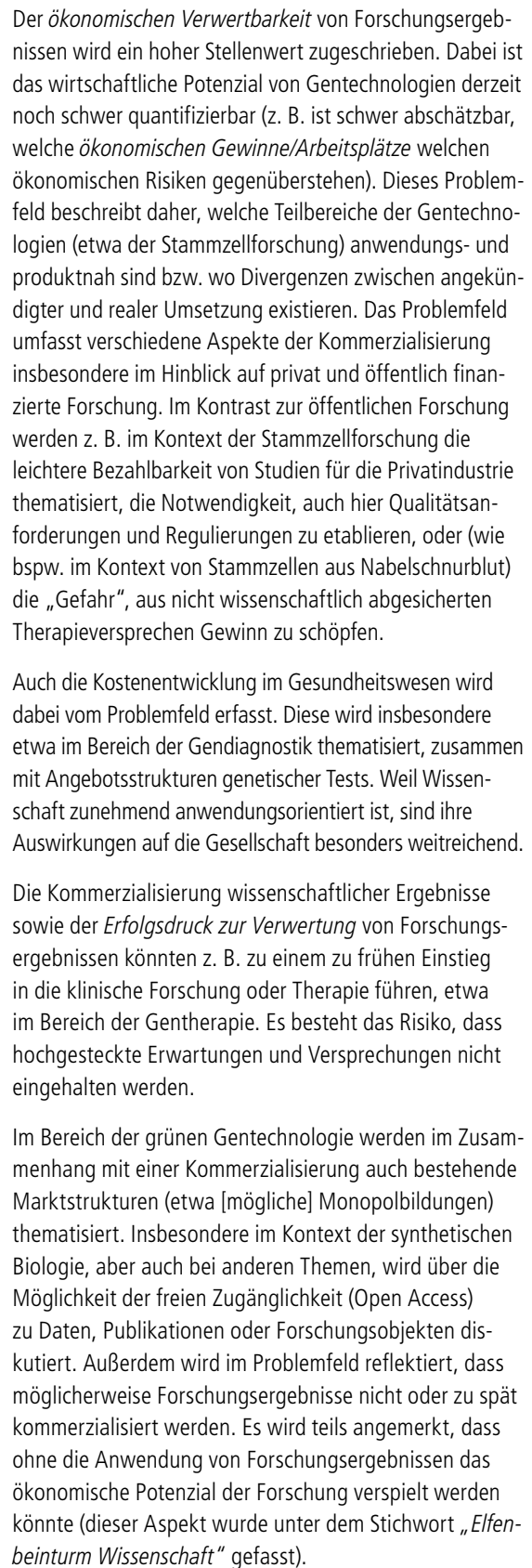 & \\
\hline
\end{tabular}




\begin{tabular}{|c|c|c|}
\hline Problemfeld & Beschreibung & Indikatoren/Beiträge \\
\hline $\begin{array}{l}\text { Patentierung } \\
\text { wissenschaftli- } \\
\text { cher Ergebnisse }\end{array}$ & $\begin{array}{l}\text { Patente gelten in anwendungsnahen Bereichen als Aus- } \\
\text { druck innovativen Forschungsgeschehens. Sie stellen in } \\
\text { besonderem Maß eine Vernetzung von Wissenschaft und } \\
\text { Wirtschaft dar, die durchaus nicht spannungsfrei ist. Bei } \\
\text { Biopatenten, die Organismen oder Teile von ihnen wie } \\
\text { einzelne Gene oder Zellen betreffen, stellt sich zudem die } \\
\text { Frage, inwiefern und in welcher Form Leben kommodifi- } \\
\text { ziert werden kann und darf, was auch unter dem Begriff } \\
\text { "Patente auf Leben“ kritisiert wird. Mögliche Verbote } \\
\text { könnten u. U. negative Auswirkungen auf Forschung und } \\
\text { Entwicklung anwendungsbezogener Technologien im Be- } \\
\text { reich der regenerativen Therapien, der Wirkstoffforschung } \\
\text { und der Pharmakotoxikologie haben. Dieses Problemfeld } \\
\text { ist für alle behandelten Themen relevant. Im Bereich der } \\
\text { Grünen Gentechnologie wird auch eine Monopolbildung } \\
\text { sowie der Missbrauch einer solchen thematisiert. }\end{array}$ & \\
\hline $\begin{array}{l}\text { Qualitäts- } \\
\text { sicherung/Arzt- } \\
\text { vorbehalt }\end{array}$ & $\begin{array}{l}\text { Das Problemfeld umfasst den Themenkomplex der } \\
\text { Standardisierung, Einhaltung von Richtlinien und der } \\
\text { Gewährleistung der Qualität, etwa bei therapeutischen } \\
\text { Anwendungen im Bereich der Stammzellforschung und } \\
\text { Gentherapie sowie der Organoidforschung oder aber auch } \\
\text { bei gendiagnostischen Angeboten von Firmen an Privat- } \\
\text { personen, die von Ärzt*innen begleitet werden sollten. }\end{array}$ & $\begin{array}{l}\text { Beiträge: } \\
\text { Mundlos (Kap. 4) } \\
\text { Fehse (Kap. 6) } \\
\text { Fehse et al. (Kap. 9) }\end{array}$ \\
\hline $\begin{array}{l}\text { Utopie der } \\
\text { Lösung globaler } \\
\text { Probleme }\end{array}$ & $\begin{array}{l}\text { Seit Beginn der Gentechnologien kursieren allgemeine } \\
\text { visionäre Vorstellungen bezüglich zukünftiger Potenziale } \\
\text { insbesondere der synthetischen Biologie sowie der } \\
\text { Grünen Gentechnologie, die versprechen, globale } \\
\text { Problemlagen wie z. B. Nahrungsmittelknappheit bzw. } \\
\text { Welthunger lösen zu können (Ernährungssicherung). }\end{array}$ & $\begin{array}{l}\text { Beiträge: } \\
\text { Fehse et al. (Kap. 9) } \\
\text { Kolleck/Sauter (Kap. 10) } \\
\text { van den Daele/Broer (Kap. 21) } \\
\text { Dederer (Kap. 22) } \\
\text { Renn (Kap. 23) }\end{array}$ \\
\hline $\begin{array}{l}\text { Nachsorge- } \\
\text { prinzip }\end{array}$ & $\begin{array}{l}\text { Das Problemfeld thematisiert (etwa im Bereich der Stamm- } \\
\text { zellforschung), dass aufwendige therapeutische Verfahren } \\
\text { gegenüber prophylaktischen bevorzugt werden könnten. } \\
\text { Die Folge wären möglicherweise höhere Gesundheits- } \\
\text { kosten für die/den Einzelne*n wie auch für die Gesellschaft } \\
\text { insgesamt. Dieser Punkt berührte z. B. bis } 2009 \text { auch die } \\
\text { Gegenüberstellung einer „Apparatemedizin“ und der } \\
\text { "ganzheitlichen“ Medizin. }\end{array}$ & \\
\hline
\end{tabular}

Die in der rechten Spalte fett markierten Indikatoren werden nachfolgend anhand detaillierter Datenblätter und Grafiken vorgestellt. 


\subsection{Indikatoren im Bereich der Gentechnologien}

In einem nächsten Schritt wurden ausgewählte Indikatoren im Bereich der Gentechnologien den Problemfeldern zugewiesen. Hierbei knüpfen wir an das Vorgehen des vierten Gentechnologieberichts an. Mithilfe standardisierter Arbeitsblätter werden im Folgenden auf bewährte Art und Weise die Indikatoren vorgestellt. Die Datenblätter geben Auskunft über die Datenquelle, die Verfügbarkeit der Daten, die Abgrenzung der Bezugsgrößen, die Gliederung der Darstellung sowie der Berechnungshäufigkeit und die Aussagefähigkeit. Der Zeitraum der Erhebung der Indikatoren erfolgte - soweit dies mithilfe der jeweiligen Quelle möglich war - ab dem Jahr 2001, dem Jahr, in dem die IAG Gentechnologiebericht ihre Arbeit aufgenommen hat.

Folgende Problemfelder wurden mithilfe von Indikatoren quantitativ beschrieben:

Realisierung Forschungsziele

- Anzahl internationaler Fachartikel zu den Themenfeldern der IAG (5B-04)

- Förderung durch den Bund zu den Themenfeldern der IAG (5B-05)

- Fördermaßnahmen der DFG zu den Themenfeldern der IAG (5B-07)

- EU-Fördermaßnahmen mit ausgewiesener deutscher Beteiligung zu den Themenfeldern der IAG (5B-08)

Forschungsstandort Deutschland

- Neuerscheinungen zu den Themenfeldern der IAG (5B-02)

- Anzahl internationaler Fachartikel zu den Themenfeldern der IAG (5B-04)

- Förderung durch den Bund zu den Themenfeldern der IAG (5B-05)

- Fördermaßnahmen der DFG zu den Themenfeldern der IAG (5B-07)

- EU-Fördermaßnahmen mit ausgewiesener deutscher Beteiligung zu den Themenfeldern der IAG (5B-08)

Öffentliche Wahrnehmung

- Mediale Abbildung der Themenfelder der IAG (5B-01)

- Neuerscheinungen zu den Themenfeldern der IAG (5B-02)

- Online-Suchanfragen zu den Themenfeldern der IAG (5B-03)

- Öffentliche Veranstaltungen zu den Themenfeldern der IAG (5B-06) 
Soziale Implikationen

- Mediale Abbildung der Themenfelder der IAG (5B-01)

- Neuerscheinungen zu den Themenfeldern der IAG (5B-02)

- Online-Suchanfragen zu den Themenfeldern der IAG (5B-03)

- Öffentliche Veranstaltungen zu den Themenfeldern der IAG (5B-06)

Gesundheitliche Risiken

- Mediale Abbildung der Themenfelder der IAG (5B-01)

- Online-Suchanfragen zu den Themenfeldern der IAG (5B-03)

Dialogverpflichtung der Forschung

- Öffentliche Veranstaltungen zu den Themenfeldern der IAG (5B-06)

Ethische Implikationen

- Mediale Abbildung der Themenfelder der IAG (5B-01)

- Neuerscheinungen zu den Themenfeldern der IAG (5B-02)

- Online-Suchanafragen zu den Themen der IAG (5B-03)

- Öffentliche Veranstaltungen zu den Themenfeldern der IAG (5B-06) 
Laufende Nr.: 5B-01

Problemfeld: Öffentliche Wahrnehmung + Soziale Implikationen + Gesundheitliche Risiken + Ethische Implikationen

INDIKATOR: MEDIALE ABBILDUNG DER THEMENFELDER DER IAG

\section{DATENQUELLE:}

Frankfurter Allgemeine Zeitung. Unter: www.faz.net

Süddeutsche Zeitung. Unter: www.sueddeutsche.de

Die Zeit. Unter: www.zeit.de

Der Spiegel. Unter: www.spiegel.de

Zugriff (alle): Januar 2021, Stand: 11.01.2021

\section{VERFÜGBARKEIT DER DATEN:}

Mehrheitlich öffentlich.

Die Recherche in den Online-Archiven der ausgewählten deutschen Zeitungen und Zeitschriften ist überwiegend, jedoch nicht ausschließlich, kostenfrei und ohne Anmeldung zugänglich. Beiträge zu den ausgewählten Suchbegriffen können tagesaktuell recherchiert werden. Einige Presseartikel können nur kostenpflichtig oder über einen Bibliotheksoder Universitätszugang abgerufen werden.

\section{ABGRENZUNG DER BERECHNUNGSGRÖSSEN:}

Für die Recherche relevanter Printartikel und Onlineartikel wurden folgende Stichwörter im Volltext ab 2001 (Beginn der IAG Gentechnologiebericht) bis 2020 (abgeschlossenes Kalenderjahr) überregional gesucht: Epigen*, Gendiagnost*, Stammzell*, Gentherap*, Grüne Gentechn*, Synth* Biol* und Organoid*. In anderen Medien erschienene Beiträge wurden dabei nicht berücksichtigt. Es wurde keine weiterführende qualitative Filterung der Suchergebnisse vorgenommen. Regionale Ausgaben und Sonderhefte wurden nicht erfasst.

\section{GLIEDERUNG DER DARSTELLUNG:}
a) Veröffentlichte Printartikel (2001-2020)
b) Summe der veröffentlichten Printartikel (2001-2020)
c) Veröffentlichte Onlineartikel (2001-2020)
d) Summe der veröffentlichten Onlineartikel (2001-2020)

\section{BERECHNUNGSHÄUFIGKEIT:}

Jährlich.

\section{AUSSAGEFÄHIGKEIT:}

Der Indikator dokumentiert die Dichte der öffentlichen Berichterstattung zu den gesuchten Stichworten im dargestellten Zeitraum in ausgewählten überregionalen Printmedien und deren Online-Angeboten. Diese erreichen - das dokumentieren die Auflagezahlen - eine Vielzahl an Menschen in ganz Deutschland, die sich auf diesem Weg über die Themenbereiche informieren können. Da die Suchbegriffe die Themenbereiche unterschiedlich gut abdecken ist der direkte Vergleich der Themen untereinander nur begrenzt aussagekräftig. 
a) Abbildung 2: Veröffentlichte Printartikel (2001-2020)



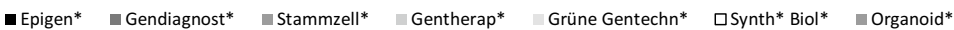

Quelle: Siehe Indikatorenblatt 5B-01.

\begin{tabular}{|l|c|c|c|c|c|c|c|c|}
\hline & Epigen* & $\begin{array}{l}\text { Gendiag- } \\
\text { nost* }^{*}\end{array}$ & $\begin{array}{l}\text { Stamm- } \\
\text { zell* }\end{array}$ & $\begin{array}{l}\text { Genthe- } \\
\text { rap* }\end{array}$ & $\begin{array}{l}\text { Grüne } \\
\text { Gentechn* }\end{array}$ & $\begin{array}{l}\text { Synth* } \\
\text { Biol* }^{*}\end{array}$ & $\begin{array}{l}\text { Orga- } \\
\text { noid* }^{*}\end{array}$ & $\begin{array}{l}\text { pro } \\
\text { Jahr }\end{array}$ \\
\hline $\mathbf{2 0 0 1}$ & 19 & 27 & 1291 & 142 & 160 & 69 & 0 & 1708 \\
\hline $\mathbf{2 0 0 2}$ & 14 & 7 & 845 & 83 & 90 & 75 & 0 & 1114 \\
\hline $\mathbf{2 0 0 3}$ & 18 & 7 & 438 & 51 & 106 & 47 & 0 & 667 \\
\hline $\mathbf{2 0 0 4}$ & 72 & 32 & 466 & 39 & 189 & 57 & 0 & 855 \\
\hline $\mathbf{2 0 0 5}$ & 53 & 36 & 478 & 28 & 123 & 55 & 0 & 773 \\
\hline $\mathbf{2 0 0 6}$ & 41 & 6 & 396 & 50 & 112 & 54 & 0 & 659 \\
\hline $\mathbf{2 0 0 7}$ & 30 & 23 & 389 & 27 & 106 & 60 & 0 & 635 \\
\hline $\mathbf{2 0 0 8}$ & 23 & 54 & 512 & 27 & 99 & 55 & 0 & 770 \\
\hline $\mathbf{2 0 0 9}$ & 25 & 34 & 226 & 20 & 190 & 61 & 0 & 556 \\
\hline $\mathbf{2 0 1 0}$ & 25 & 18 & 150 & 18 & 81 & 65 & 0 & 357 \\
\hline $\mathbf{2 0 1 1}$ & 21 & 17 & 125 & 8 & 60 & 53 & 0 & 284 \\
\hline $\mathbf{2 0 1 2}$ & 20 & 29 & 114 & 16 & 60 & 59 & 0 & 298 \\
\hline $\mathbf{2 0 1 3}$ & 23 & 17 & 152 & 15 & 60 & 57 & 4 & 328 \\
\hline $\mathbf{2 0 1 4}$ & 22 & 5 & 122 & 14 & 86 & 28 & 0 & 277 \\
\hline $\mathbf{2 0 1 5}$ & 24 & 4 & 105 & 35 & 61 & 71 & 5 & 305 \\
\hline $\mathbf{2 0 1 6}$ & 29 & 8 & 108 & 39 & 57 & 58 & 1 & 300 \\
\hline $\mathbf{2 0 1 7}$ & 33 & 8 & 125 & 51 & 42 & 56 & 5 & 320 \\
\hline $\mathbf{2 0 1 8}$ & 33 & 9 & 121 & 61 & 47 & 57 & 17 & 345 \\
\hline $\mathbf{2 0 1 9}$ & 26 & 20 & 109 & 75 & 22 & 50 & 10 & 312 \\
\hline $\mathbf{2 0 2 0}$ & 22 & 12 & 73 & 42 & 28 & 64 & 10 & 251 \\
\hline $\mathbf{S u m m e}$ & $\mathbf{5 7 3}$ & $\mathbf{3 7 3}$ & $\mathbf{6 3 4 5}$ & $\mathbf{8 4 1}$ & $\mathbf{1 7 7 9}$ & $\mathbf{1 1 5 1}$ & $\mathbf{4 2}$ & $\mathbf{1 1 1 0 4}$ \\
\hline
\end{tabular}


b) Abbildung 3: Summe der veröffentlichten Printartikel (2001-2020)

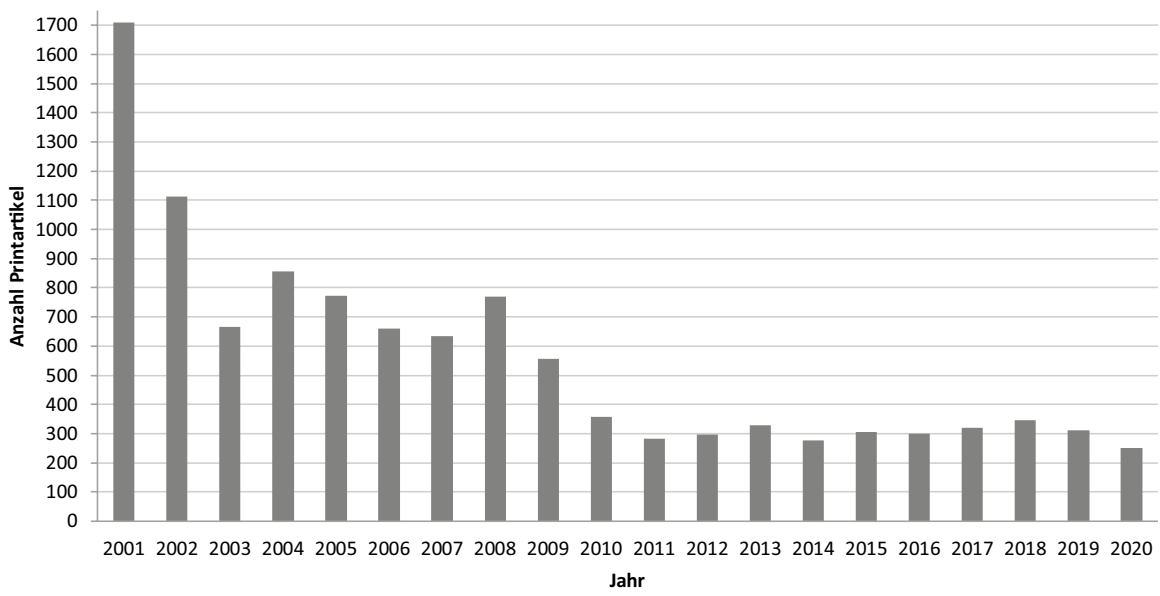

n Summe der Printartikel

Quelle: Siehe Indikatorblatt 5B-01.

c) Abbildung 4: Veröffentlichte Onlineartikel (2001-2020)





Quelle: Siehe Indikatorenblatt 5B-01. 


\begin{tabular}{|l|c|c|c|c|c|c|c|c|}
\hline & Epigen** & $\begin{array}{l}\text { Gendiag- } \\
\text { nost* }^{*}\end{array}$ & $\begin{array}{l}\text { Stamm- } \\
\text { zell* }\end{array}$ & $\begin{array}{l}\text { Genthe- } \\
\text { rap* }\end{array}$ & $\begin{array}{l}\text { Grüne } \\
\text { Gentechn* }\end{array}$ & $\begin{array}{l}\text { Synth* } \\
\text { Biol* }^{*}\end{array}$ & $\begin{array}{l}\text { Orga- } \\
\text { noid* }\end{array}$ & $\begin{array}{l}\text { pro } \\
\text { Jahr }\end{array}$ \\
\hline $\mathbf{2 0 0 1}$ & 1 & 0 & 75 & 21 & 57 & 3 & 0 & 157 \\
\hline $\mathbf{2 0 0 2}$ & 4 & 1 & 78 & 7 & 24 & 7 & 0 & 121 \\
\hline $\mathbf{2 0 0 3}$ & 1 & 1 & 26 & 1 & 16 & 5 & 0 & 50 \\
\hline $\mathbf{2 0 0 4}$ & 4 & 4 & 65 & 10 & 25 & 11 & 0 & 119 \\
\hline $\mathbf{2 0 0 5}$ & 5 & 7 & 60 & 4 & 54 & 9 & 0 & 139 \\
\hline $\mathbf{2 0 0 6}$ & 6 & 1 & 54 & 6 & 13 & 10 & 0 & 90 \\
\hline $\mathbf{2 0 0 7}$ & 1 & 4 & 80 & 9 & 18 & 12 & 0 & 124 \\
\hline $\mathbf{2 0 0 8}$ & 4 & 9 & 137 & 14 & 26 & 12 & 0 & 202 \\
\hline $\mathbf{2 0 0 9}$ & 9 & 13 & 74 & 12 & 94 & 40 & 0 & 242 \\
\hline $\mathbf{2 0 1 0}$ & 13 & 13 & 39 & 10 & 42 & 21 & 0 & 138 \\
\hline $\mathbf{2 0 1 1}$ & 5 & 5 & 48 & 5 & 30 & 26 & 0 & 119 \\
\hline $\mathbf{2 0 1 2}$ & 13 & 20 & 86 & 10 & 40 & 40 & 0 & 209 \\
\hline $\mathbf{2 0 1 3}$ & 17 & 14 & 88 & 9 & 23 & 24 & 7 & 182 \\
\hline $\mathbf{2 0 1 4}$ & 17 & 3 & 117 & 8 & 67 & 27 & 0 & 239 \\
\hline $\mathbf{2 0 1 5}$ & 8 & 2 & 64 & 12 & 39 & 45 & 6 & 176 \\
\hline $\mathbf{2 0 1 6}$ & 16 & 4 & 65 & 15 & 25 & 18 & 4 & 147 \\
\hline $\mathbf{2 0 1 7}$ & 11 & 1 & 97 & 35 & 18 & 28 & 2 & 192 \\
\hline $\mathbf{2 0 1 8}$ & 14 & 9 & 72 & 26 & 24 & 24 & 21 & 190 \\
\hline $\mathbf{2 0 1 9}$ & 12 & 6 & 61 & 15 & 17 & 25 & 12 & 148 \\
\hline $\mathbf{2 0 2 0}$ & 17 & 9 & 65 & 24 & 42 & 45 & 7 & 209 \\
\hline Summe & $\mathbf{1 7 8}$ & $\mathbf{1 2 6}$ & $\mathbf{1 4 5 1}$ & $\mathbf{2 5 3}$ & $\mathbf{6 9 4}$ & $\mathbf{4 3 2}$ & $\mathbf{5 2}$ & $\mathbf{3 1 8 6}$ \\
\hline
\end{tabular}

d) Abbildung 5: Summe der veröffentlichten Onlineartikel (2001-2020)

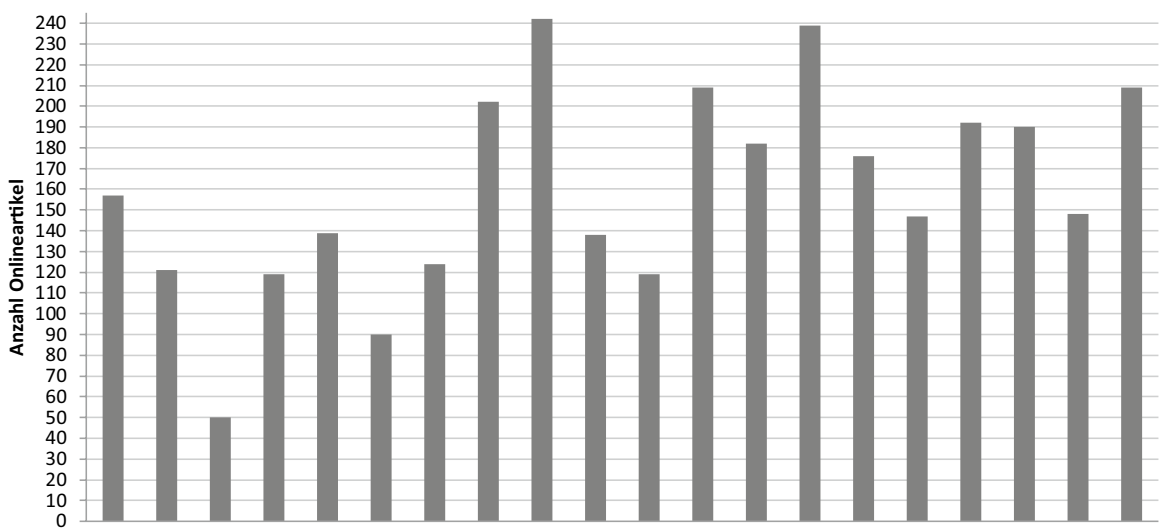

20012002200320042005200620072008200920102011201220132014201520162017201820192020 Jahr 
Laufende Nr.: 5B-02

Problemfeld: Forschungsstandort Deutschland + Öffentliche Wahrnehmung + Soziale Implikationen + Ethische Implikationen

\section{INDIKATOR: NEUERSCHEINUNGEN ZU DEN THEMENFELDERN DER IAG}

\section{DATENQUELLE:}

Online-Katalog der Deutschen Nationalbibliothek. Unter: https://portal.dnb.de

Zugriff: Januar 2021, Stand: 19.01.2021

\section{VERFÜGBARKEIT DER DATEN:}

Öffentlich.

Die Nationalbibliothek (DNB) ist eine bundesunmittelbare Anstalt des öffentlichen Rechts. Ihre Aufgabe ist die Archivierung und bibliografische Erfassung in Deutschland veröffentlichter Medienwerke (Monografien, Zeitungen, Zeitschriften, Loseblattwerke, Karten, Musikalien, Tonträger, elektrische Publikationen). Darüber hinaus werden auch im Ausland veröffentlichte deutschsprachige Medienwerke, im Ausland veröffentlichte Übersetzungen deutschsprachiger Medienwerke, fremdsprachige Medienwerke über Deutschland sowie Exilpublikationen deutschsprachiger Emigrant*innen zwischen 1933 und 1950 erfasst. Seit 2006 werden zusätzlich Online-Publikationen systematisch berücksichtigt. Der Katalog der DNB erlaubt eine kostenlose Recherche innerhalb der umfassenden Bibliotheksbestände seit 1913. Nach Anbieterangaben werden eingegangene Publikationen mit einer Bearbeitungszeit von ca. einem Monat in den Katalog und in die Deutsche Nationalbibliografie eingetragen.

\section{ABGRENZUNG DER BERECHNUNGSGRÖSSEN:}

Für die Recherche relevanter deutschsprachiger Titel wurden die Suchbegriffe „Epigen*”, "Gendiagnost* , "Stamm-

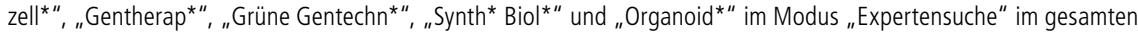
Bestand des Katalogs der Deutschen Nationalbibliolthek ab 2001 (Beginn des Gentechnologieberichts) gesucht. Da es sich um eine Suche nach einem speziellen Begriff handelt, wurde eine über die Titelfelder hinausgehende Suchfunktion (Index=woe) verwendet. Im Bestand vermerkte Hochschulschriften wurden explizit ausgenomen, da sie für die/den interessierte ${ }^{*}$ Lai* ${ }^{*}$ schwer zugänglich sind. Generell ausgeschlossen wurden Periodika sowie Normdaten für einzelne Personen, Organisationen, Veranstaltungen, Geografika, Sachbegriffe und Werktitel, die im Katalog der DNB geführt werden. Doppelnennungen (Physische und Online-Publikation) wurden händisch aussortiert. Es wurde keine weiterführende qualitative Filterung der Suchergebnisse vorgenommen.

\section{GLIEDERUNG DER DARSTELLUNG:}

a) Anzahl an Neuerscheinungen (2001-2020)

b) Summe der Neuerscheinungen (2001-2020)

\section{BERECHNUNGSHÄUFIGKEIT:}

Jährlich.

\section{AUSSAGEFÄHIGKEIT:}

Der Indikator dokumentiert die publizistische Dichte für die verschiedenen Themenbereiche. Er zählt diejenigen Materialien, die auch der interessierten Öffentlichkeit frei zur Verfügung stehen. Über die (etwa in Fachjournalen geführte) wissenschaftsinterne Aushandlung liefert er keine Aussage. Da die Suchbegriffe die Themenbereiche unterschiedlich gut abdecken, ist der direkte Vergleich der Themen untereinander nur begrenzt aussagekräftig. 
a) Abbildung 6: Anzahl an Neuerscheinungen (2001-2020)

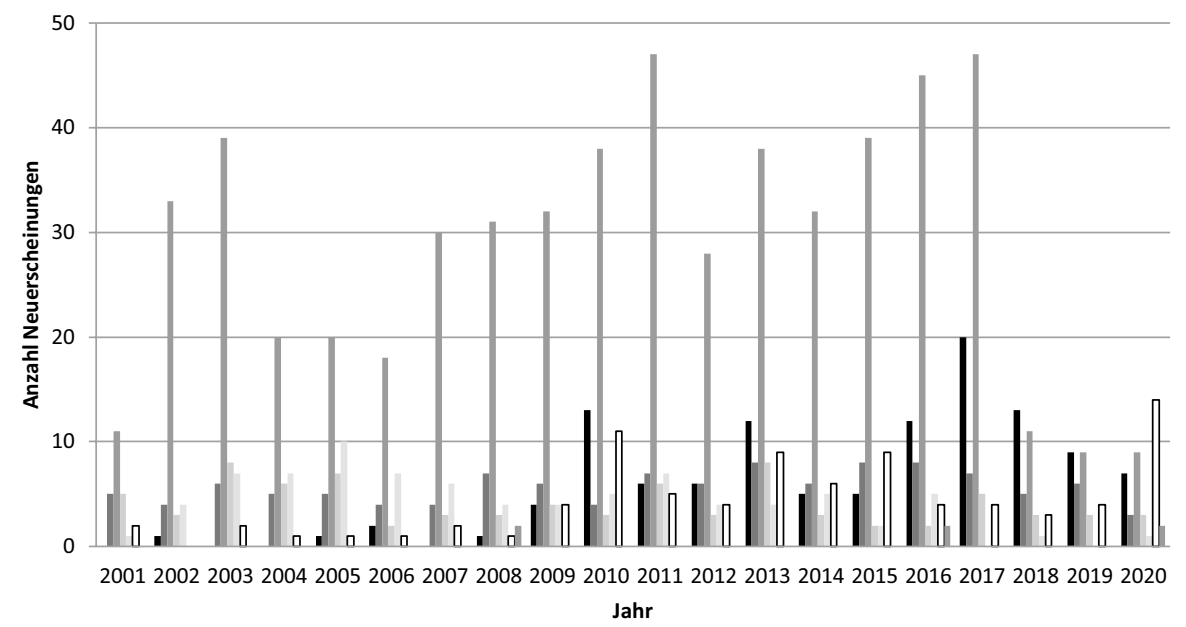



Erfassung der im DNB-Katalog verzeichneten Titel bis zum Stichtag am 19.01.2021. Erweiterter Recherchemodus; Unterschiede zu frühreren Veröffentlichungen möglich.

Quelle: Siehe Indikatorenblatt 5B-02.

\begin{tabular}{|l|c|c|c|c|c|c|c|}
\hline & Epigen* & $\begin{array}{l}\text { Gendiag- } \\
\text { nost* }^{*}\end{array}$ & $\begin{array}{l}\text { Stamm- } \\
\text { zell* }\end{array}$ & $\begin{array}{l}\text { Genthe- } \\
\text { rap* }\end{array}$ & $\begin{array}{l}\text { Grüne } \\
\text { Gentechn* }\end{array}$ & $\begin{array}{l}\text { Synth* } \\
\text { Biol* }^{*}\end{array}$ & $\begin{array}{l}\text { Orga- } \\
\text { noid* }^{*}\end{array}$ \\
\hline $\mathbf{2 0 0 1}$ & 0 & 5 & 11 & 5 & 1 & 2 & 0 \\
\hline $\mathbf{2 0 0 2}$ & 1 & 4 & 33 & 3 & 4 & 0 & 0 \\
\hline $\mathbf{2 0 0 3}$ & 0 & 6 & 39 & 8 & 7 & 2 & 0 \\
\hline $\mathbf{2 0 0 4}$ & 0 & 5 & 20 & 6 & 7 & 1 & 0 \\
\hline $\mathbf{2 0 0 5}$ & 1 & 5 & 20 & 7 & 10 & 1 & 0 \\
\hline $\mathbf{2 0 0 6}$ & 2 & 4 & 18 & 2 & 7 & 1 & 0 \\
\hline $\mathbf{2 0 0 7}$ & 0 & 4 & 30 & 3 & 6 & 2 & 0 \\
\hline $\mathbf{2 0 0 8}$ & 1 & 7 & 31 & 3 & 4 & 1 & 2 \\
\hline $\mathbf{2 0 0 9}$ & 4 & 6 & 32 & 4 & 4 & 4 & 0 \\
\hline $\mathbf{2 0 1 0}$ & 13 & 4 & 38 & 3 & 5 & 11 & 0 \\
\hline $\mathbf{2 0 1 1}$ & 6 & 7 & 47 & 6 & 7 & 5 & 0 \\
\hline $\mathbf{2 0 1 2}$ & 6 & 6 & 28 & 3 & 4 & 4 & 0 \\
\hline $\mathbf{2 0 1 3}$ & 12 & 8 & 38 & 8 & 4 & 9 & 0 \\
\hline $\mathbf{2 0 1 4}$ & 5 & 6 & 32 & 3 & 5 & 6 & 0 \\
\hline
\end{tabular}




\begin{tabular}{|l|c|c|c|c|c|c|c|}
\hline & Epigen* & $\begin{array}{l}\text { Gendiag- } \\
\text { nost* }\end{array}$ & $\begin{array}{l}\text { Stamm- } \\
\text { zell* }\end{array}$ & $\begin{array}{l}\text { Genthe- } \\
\text { rap* }\end{array}$ & $\begin{array}{l}\text { Grüne } \\
\text { Gentechn* }\end{array}$ & $\begin{array}{l}\text { Synth* } \\
\text { Biol* }\end{array}$ & $\begin{array}{l}\text { Orga- } \\
\text { noid* }\end{array}$ \\
\hline $\mathbf{2 0 1 5}$ & 5 & 8 & 39 & 2 & 2 & 9 & 0 \\
\hline $\mathbf{2 0 1 6}$ & 12 & 8 & 45 & 2 & 5 & 4 & 2 \\
\hline $\mathbf{2 0 1 7}$ & 20 & 7 & 47 & 5 & 0 & 4 & 0 \\
\hline $\mathbf{2 0 1 8}$ & 13 & 5 & 11 & 3 & 1 & 3 & 0 \\
\hline $\mathbf{2 0 1 9}$ & 9 & 6 & 9 & 3 & 0 & 4 & 0 \\
\hline $\mathbf{2 0 2 0}$ & 7 & 3 & 9 & 3 & 1 & 14 & 2 \\
\hline Summe & $\mathbf{1 1 7}$ & $\mathbf{1 1 4}$ & $\mathbf{5 7 7}$ & $\mathbf{8 2}$ & $\mathbf{8 4}$ & $\mathbf{8 7}$ & $\mathbf{6}$ \\
\hline
\end{tabular}

b) Abbildung 7: Summe der Neuerscheinungen (2001-2020)

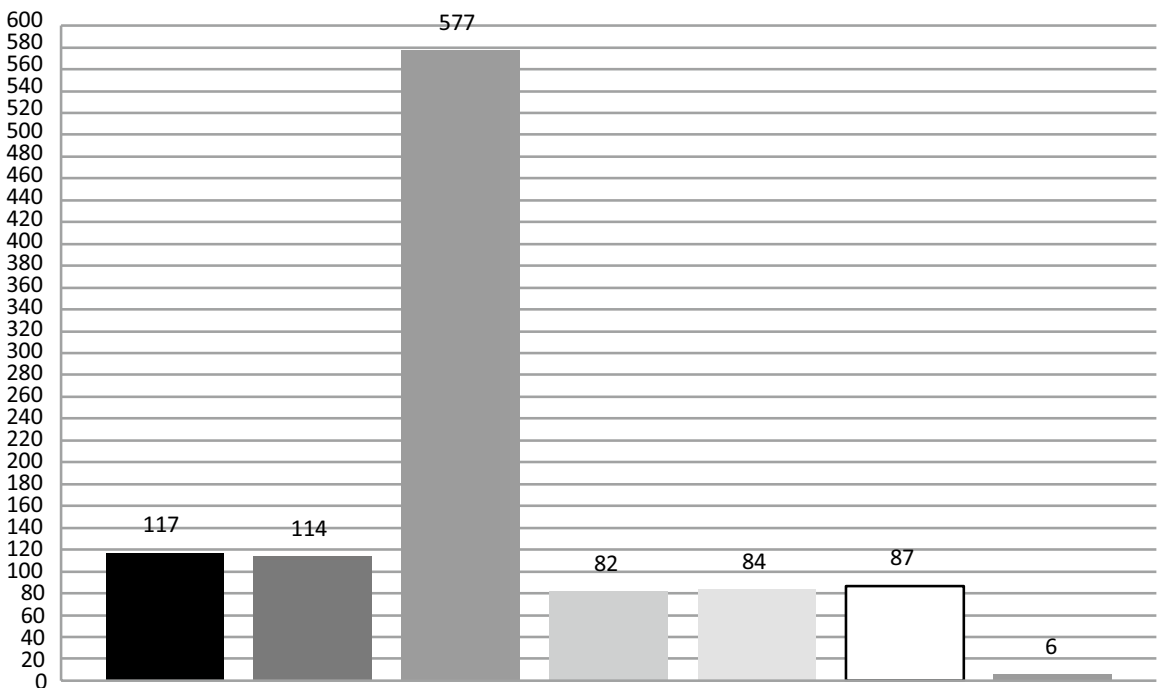

Summe der Neuerscheinungen (2001-2020)

$\begin{array}{lll}\text { घ Epigen* } & \square \text { Gendiagnost* } & \text { Stammzell* } \\ \text { Grüne Gentechn* } & \square \text { Synth* Biol* } & \text { Organoid* }\end{array}$

Erfassung der im DNB-Katalog verzeichneten Titel bis zum Stichtag am 19.01.2021. Erweiterter Recherchemodus; Unterschiede zu früheren Veröffentlichungen möglich.

Quelle: Siehe Indikatorenblatt 5B-02. 
Laufende Nr.: 5B-03

Problemfeld: Öffentliche Wahrnehmung + Soziale Implikationen + Gesundheitliche Risiken + Ethische Implikationen

\section{INDIKATOR: ONLINE-SUCHANFRAGEN ZU DEN THEMENFELDERN DER IAG}

\section{DATENQUELLE:}

Google Trends. Unter: https://www.google.com/trends/

Zugriff: Januar 2021, Stand: 13.01.2021

\section{VERFÜGBARKEIT DER DATEN:}

Öffentlich.

Kostenloses Online-Analyse-Tool der Firma Google, das einen prozentualen Anteil der Sucheingaben in die Google Websuche analysiert. Der verwendete Analysealgorithmus und absolute Zahlen zu den Suchanfragen sind nicht öffentlich zugänglich. Daten ab 2004 sind einsehbar und spiegeln die Nachfrage eines bestimmten Suchbegriffs in Relation zum gesamten Suchaufkommen in Google innerhalb einer ausgewählten Zeitspanne. Die Werte werden normiert von 0 bis 100 dargestellt, wobei 100 den Datenpunkt mit der höchsten relativen Nachfrage innerhalb der ausgewählten Zeitspanne kennzeichnet. Regionale Unterschiede im gesamten Suchaufkommen werden ebenfalls normalisiert, um Vergleichbarkeit zwischen einzelnen Ländern zu ermöglichen. Nicht für alle Suchbegriffe liegen ausreichend Daten vor ( "Suchvolumen ist zu gering" = 0). Vorhandene Daten können bei Anmeldung mit einem Google-Konto als CSV-Datei exportiert werden. Es besteht die Möglichkeit, Suchergebnisse nach Regionen (Länder, Städte) und festgelegten Sachkategorien zu filtern. Zudem können mehrere Stichworte gleichzeitig abgefragt werden.

\section{ABGRENZUNG DER BERECHNUNGSGRÖSSEN:}

Für die Recherche wurden die Stichwörter "Grüne Gentechnologie", "Gentherapie”, „Stammzellforschung", "Epigenetik", "Gendiagnostik", "Synthetische Biologie" und "Organoide" verwendet (Trunkierungen wie epigen* sind nicht möglich). Es wurden die Daten für Deutschland im Zeitraum Januar 2004 bis Dezember 2020 gesucht; alle Kategorien wurden einbezogen. Die Angaben für die einzelnen Monate wurden händisch übernommen.

\section{GLIEDERUNG DER DARSTELLUNG:}

Relative Nachfrage nach den Stichwörtern in der Google Websuche Deutschland (2004-2020, 01.04.2004-

31.12.2020) (Google Trends):

a) Epigenetik

b) Gendiagnostik

c) Stammzellforschung

d) Gentherapie

e) Grüne Gentechnologie

f) Synthetische Biologie

g) Organoide

\section{BERECHNUNGSHÄUFIGKEIT:}

Monatlich.

\section{AUSSAGEFÄHIGKEIT:}

Die Mehrheit der Bevölkerung in Deutschland nutzt mittlerweile das Internet fast täglich für private Zwecke $88 \%$ in 2018, https://www.destatis.de/DE/Themen/Querschnitt/Jahrbuch/jb-kultur-medien-freizeit.pdf?__blob=publicationFile [28.10.2020]): u. a. für die Suche nach Informationen und zur Aneignung von Wissen. Zentral ist hierbei das Auffinden der Daten; eine erste Anlaufstelle sind meist Internet-Suchmaschinen. In Deutschland wird überwiegend Google genutzt (https://de.statista.com/statistik/daten/studie/301012/umfrage/marktanteile-der-suchmaschinen-und-marktanteile-mobile-suche/ [28.10.2020]). Online-Suchanfragen werden daher als Indikator für das öffentliche Interesse für bestimmte Themen gewertet. Suchmaschinen-Daten werden entsprechend bereits wirtschaftlich und wissenschaftlich genutzt, z. B. für Marketingzwecke oder für epidemiologische Fragestellungen. Die in Google Trends abgebildete 
relative Nachfrage nach den Stichwörtern in der Google Websuche dokumentiert das öffentliche Interesse an den Themen über die Jahre. Es ist dabei zu beachten, dass der Analysealgorithmus von Google Trends und etwaige Weiterentwicklungen nicht einsehbar sind. Auch sind keine absoluten Zahlen erhältlich. Ein Aufwärtstrend des relativen Suchvolumens bedeutet daher nicht unbedingt eine quantitative Zunahme der Suchanfragen zum jeweiligen Stichwort. Auch beruhen die Trend-Berechnungen nur auf Stichproben, was bei wenig nachgefragten Stichworten problematisch ist. Die mögliche Mehrdeutigkeit von Suchbegriffen ist ebenfalls zu berücksichtigen. Die hier verwendeten Stichwörter und der Filter auf Deutschland stellen allerdings einen eindeutigen Themenbezug sicher. Aus den Daten ist nicht direkt ersichtlich, aus welchem Anlass oder über welchen Aspekt des Themengebiets konkret Informationen gesucht wurden.

a) Abbildung 8: Relative Nachfrage nach dem Stichwort „Epigenetik" in Google (2004-2020)

(Google Trends)

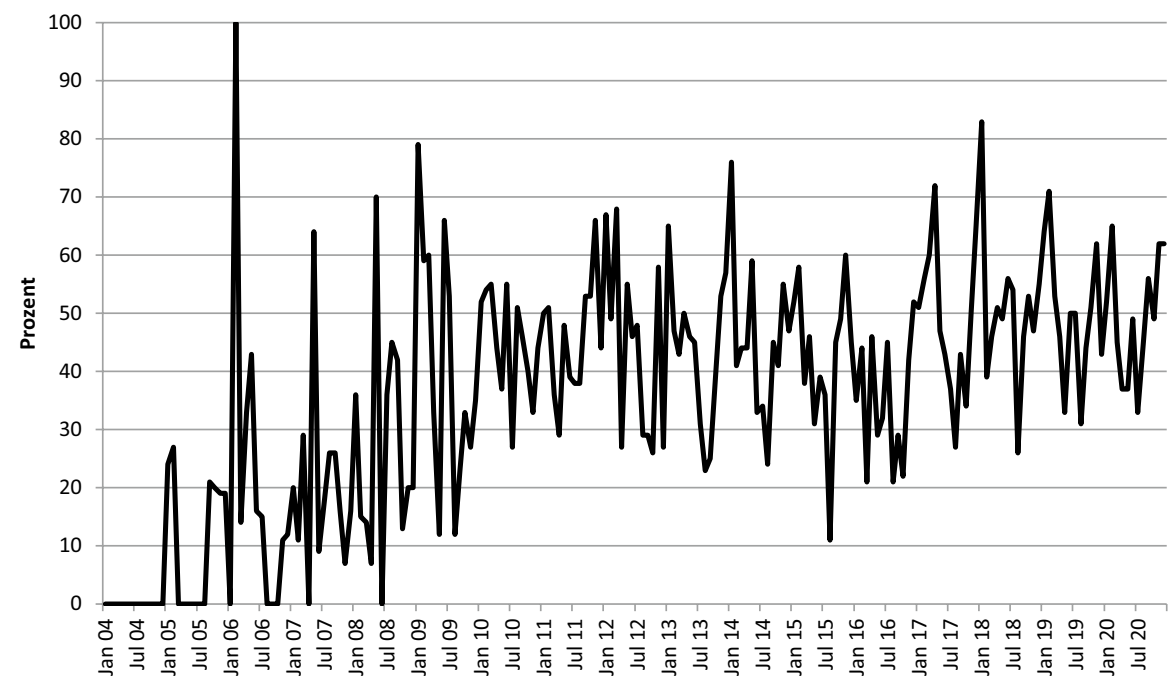

Recherche am 13.01.2021.

Quelle: Siehe Indikatorblatt 5B-03. 
b) Abbildung 9: Relative Nachfrage nach dem Stichwort "Gendiagnostik" in Google (2004-2020) (Google Trends)

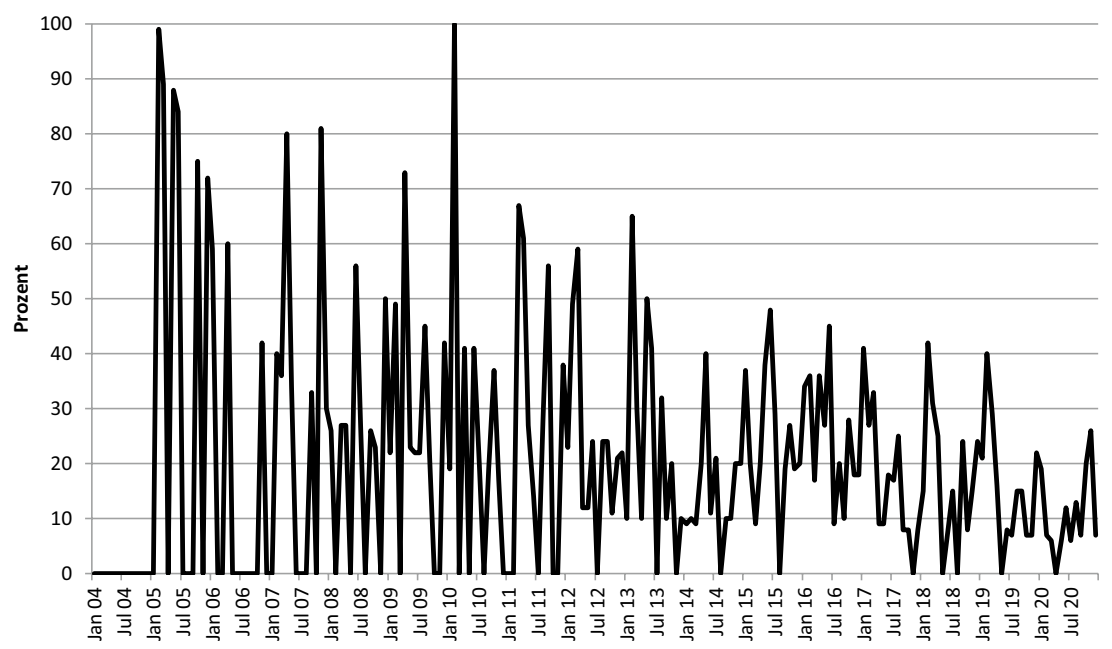

Recherche am 13.01.2021.

Quelle: Siehe Indikatorblatt 5B-03.

c) Abbildung 10: Relative Nachfrage nach dem Stichwort "Stammzellforschung" in Google (2004-2020) (Google Trends)

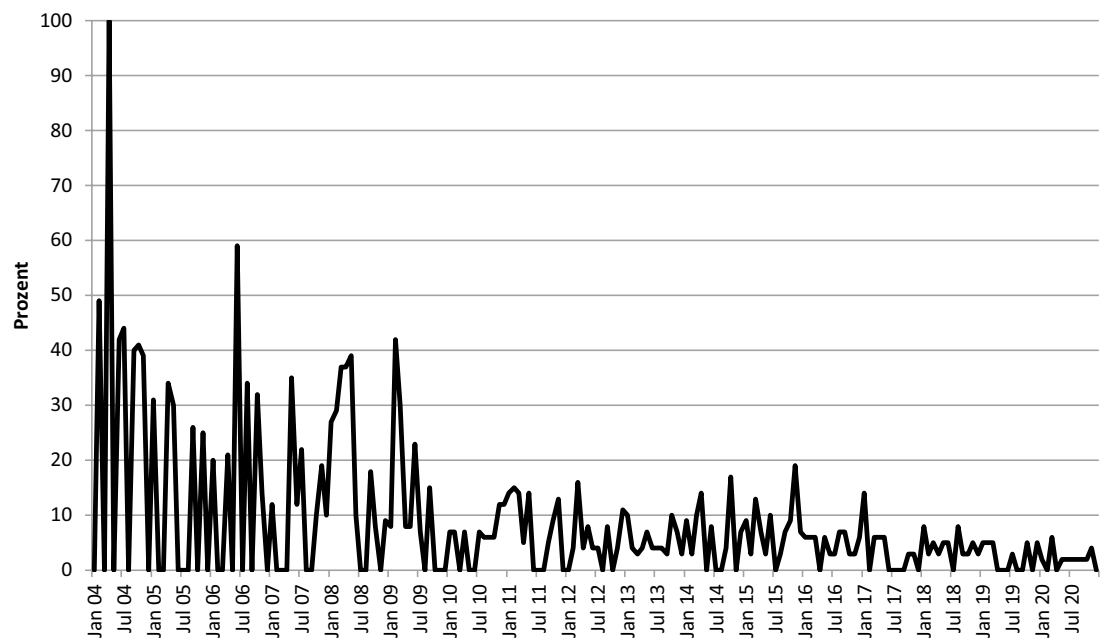

Recherche am 13.01.2021.

Quelle: Siehe Indikatorblatt 5B-03. 
d) Abbildung 11: Relative Nachfrage nach dem Stichwort "Gentherapie" in Google (2004-2020) (Google Trends)

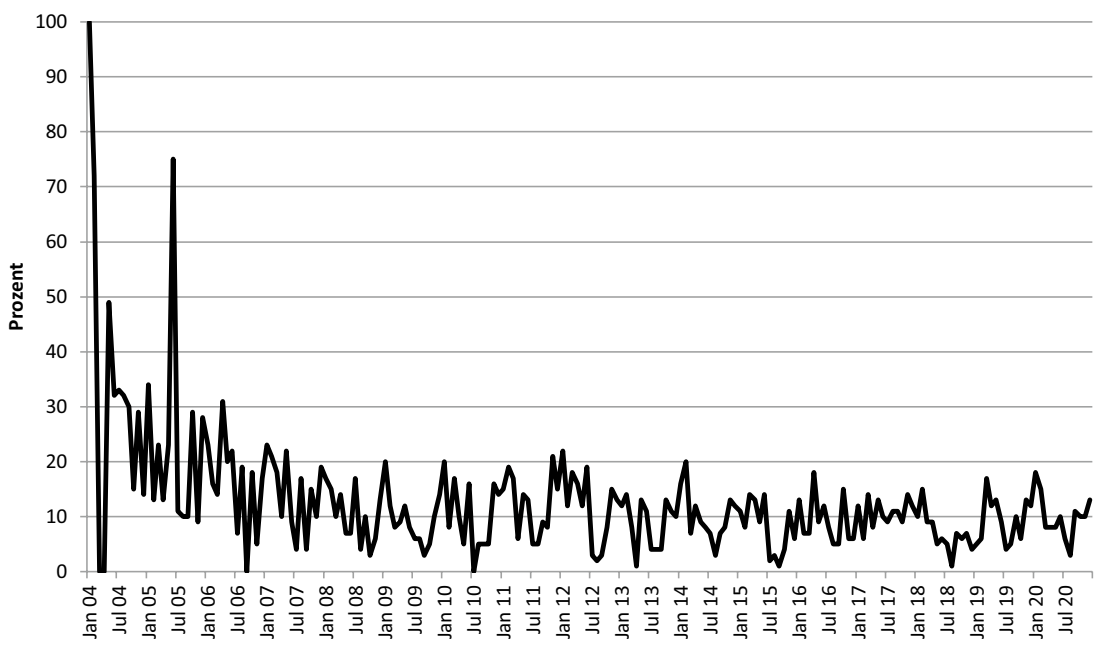

Recherche am 13.01.2021.

Quelle: Siehe Indikatorblatt 5B-03.

e) Abbildung 12: Relative Nachfrage nach dem Stichwort "Grüne Gentechnologie" in Google (2004-2020) (Google Trends)

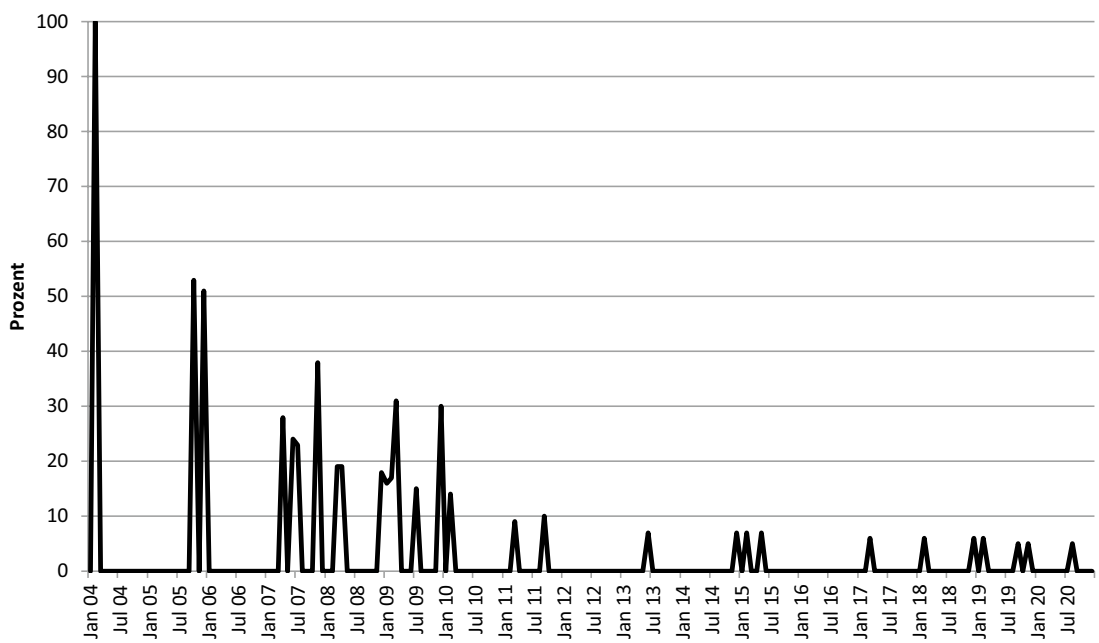

Recherche am 13.01.2021.

Quelle: Siehe Indikatorblatt 5B-03. 
f) Abbildung 13: Relative Nachfrage nach dem Stichwort "Synthetische Biologie" (2004-2020) (Google Trends)

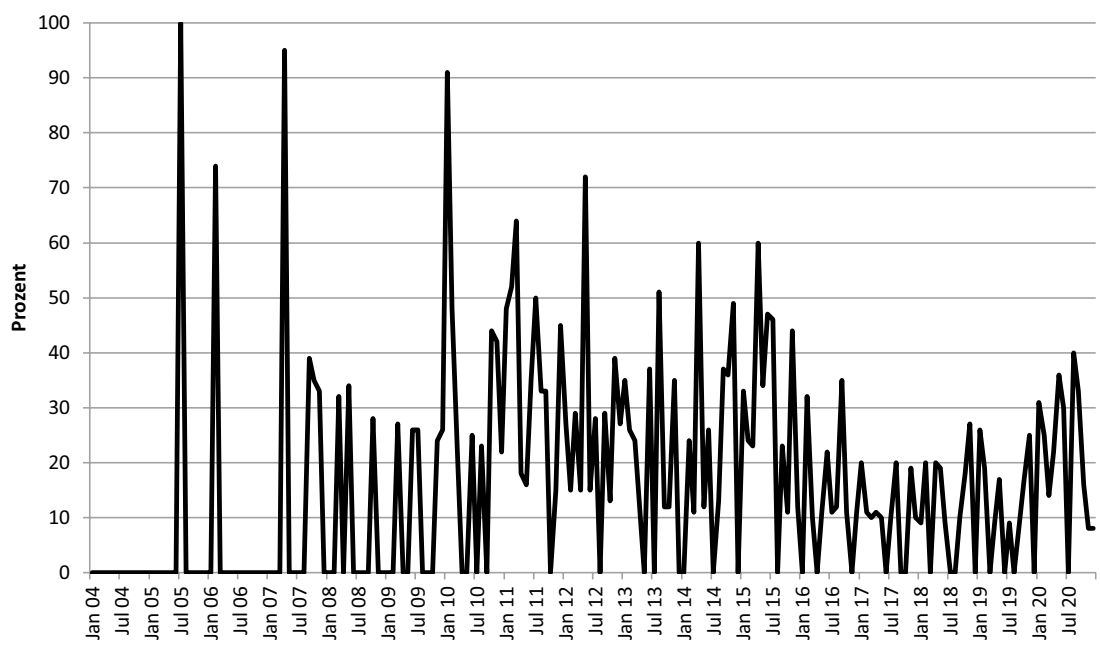

Recherche am 13.01.2021.

Quelle: Siehe Indikatorblatt 5B-03.

g) Abbildung 14: Relative Nachfrage nach dem Stichwort „Organoide” (2004-2020) (Google Trends)

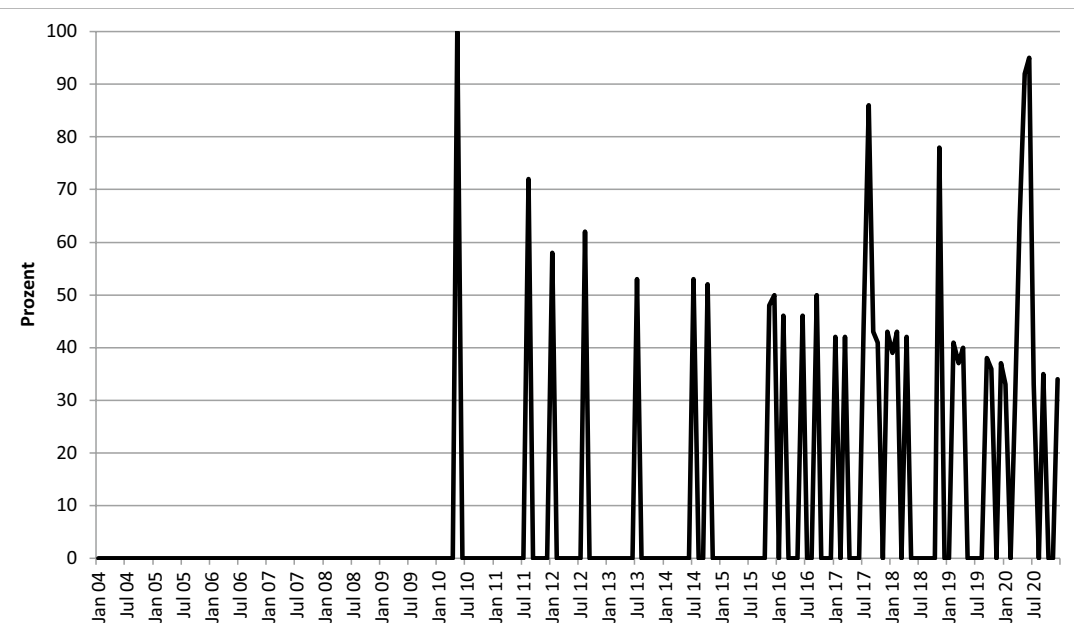

Recherche am 13.01.2021.

Quelle: Siehe Indikatorblatt 5B-03. 
Laufende Nr.: 5B-04

Problemfeld: Realisierung Forschungsziele + Forschungsstandort Deutschland

\section{INDIKATOR: ANZAHL INTERNATIONALER FACHARTIKEL ZU DEN THEMENFELDERN DER IAG}

\section{DATENQUELLE:}

Scopus - Zitationsdatenbank. Unter: https://www.scopus.com/home.uri

Zugriff: Januar 2021, Stand: 11.01.2021

\section{VERFÜGBARKEIT DER DATEN:}

Kostenpflichtige Datenbank.

Zugang über öffentliche Bibliotheken und andere Einrichtungen möglich, die eine Lizenz erworben haben.

Scopus ist die größte Datenbank für peer-reviewed Literatur. Dazu zählen überwiegend wissenschaftliche Journale, aber auch Bücher und Konferenzbeiträge. Sie umfasst mehr als 69 Millionen Einträge aus verschiedenen Disziplinen.

\section{ABGRENZUNG DER BERECHNUNGSGRÖSSEN:}

Für die Recherche wurden einschlägige Stichworte (= Epigen*, Genetic diagnos*, Stem cell*, Gene* therap*, Agr* biotechn*, Synth* biolog*, Organoid*) mit einer Trunkierung verwendet. Analog zu ähnlichen Indikatoren, die Publikationsaufkommen erfassen, wurde ausschließlich nach englischsprachigen Fachartikeln gesucht. Hierbei ausgeschlossen wurde die Suche in den Kategorien "Earth and Planetary Sciences" und "Energy". Zusätzlich wurden noch die Autor*innenschaften aus Deutschland identifiziert. Die Daten sind hier ab 2001, dem Jahr in dem der Gentechnologiebericht seine Arbeit aufgenommen hat, dargestellt.

\section{GLIEDERUNG DER DARSTELLUNG:}
a) Internationale Fachpublikationen (2001-2020)
b) Summe der internationalen Fachpublikationen (2001-2020)
c) Internationale Fachpublikationen mit deutscher Autor*innenschaft (2001-2020)
d) Summe der internationalen Fachpublikationen mit deutscher Autor*innenschaft (2001-2020)

\section{BERECHNUNGSHÄUFIGKEIT:}

Jährlich.

\section{AUSSAGEFÄHIGKEIT:}

Der Indikator spiegelt die weltweiten Forschungsaktivitäten zu unterschiedlichen Themenbereichen wider. Anhand des Umfangs der veröffentlichten Publikationen kann beobachtet werden, wie intensiv ein Themenbereich über die Jahre beforscht wird und welche Länder jeweils eine Vorrangstellung im „internationalen Forschungswettlauf" einnehmen. Dabei ist zu berücksichtigen, dass trotz des großen Umfangs der Datenbank keine vollständige Erfassung der Zitationen erwartet werden kann: Relevante Veröffentlichungen sind unter Umständen von vornherein nicht in der Datenbank enthalten oder nicht unter den verwendeten Schlagworten zu finden. Ebenfalls muss beachtet werden, dass eine Veröffentlichung eine gleichwertige Kollaboration von Autor*innen mehrerer Länder darstellen kann, wobei die Scopus-Datenbank hier die Landeszugehörigkeit aller Autor*innen standardmäßig erfasst, nicht jedoch, in welcher Reihenfolge die Autor*innen stehen und ob es sich um eine Erstautor*innenschaft handelt.

Die Darstellung für 2020 ist möglicherweise unvollständig, da eventuell noch nicht alle Veröffentlichungen in der Datenbank aufgenommen sind. 
a) Abbildung 15: Internationale Fachpublikationen (2001-2020)

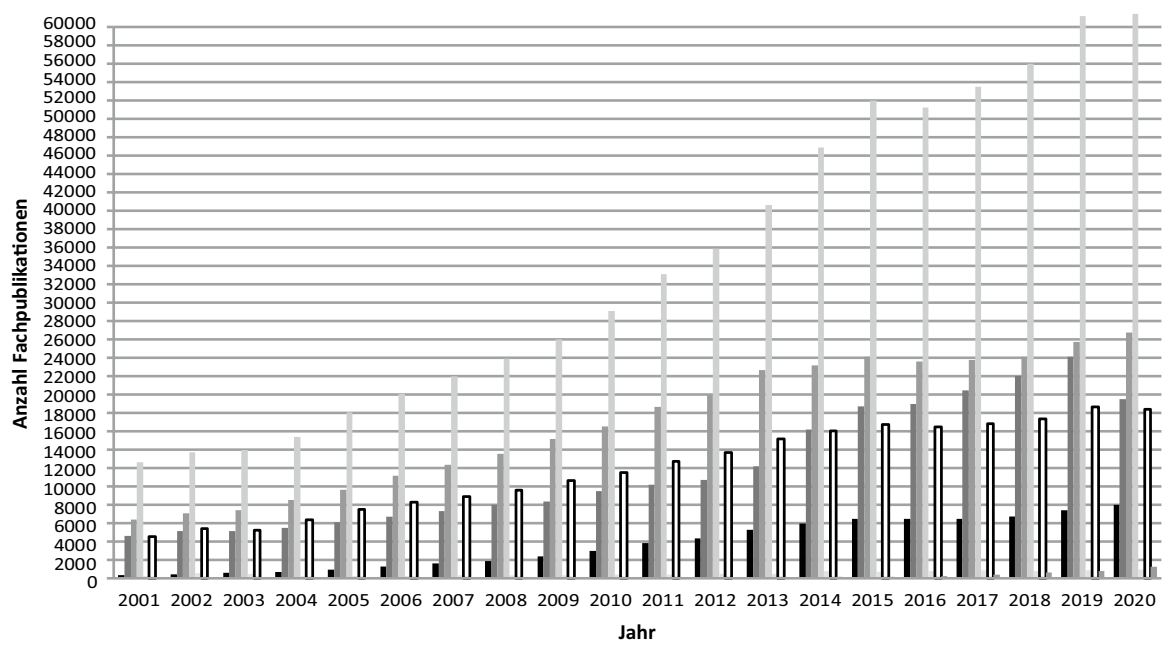

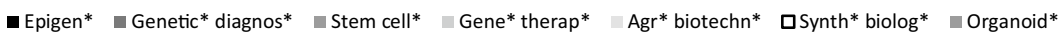

Quelle: Siehe Indikatorenblatt 5B-04.

\begin{tabular}{|l|c|c|c|c|c|c|c|}
\hline $\begin{array}{l}\text { Inter- } \\
\text { national }\end{array}$ & Epigen* & $\begin{array}{l}\text { Gendiag- } \\
\text { nost* }\end{array}$ & $\begin{array}{l}\text { Stamm- } \\
\text { zell* }\end{array}$ & $\begin{array}{l}\text { Genthe- } \\
\text { rap* }\end{array}$ & $\begin{array}{l}\text { Grüne } \\
\text { Gentechn* }\end{array}$ & $\begin{array}{l}\text { Synth* } \\
\text { Biol* }^{*}\end{array}$ & $\begin{array}{l}\text { Orga- } \\
\text { noid* }^{*}\end{array}$ \\
\hline $\mathbf{2 0 0 1}$ & 359 & 4401 & 6215 & 12541 & 256 & 4343 & 30 \\
\hline $\mathbf{2 0 0 2}$ & 440 & 4913 & 6915 & 13604 & 562 & 5112 & 24 \\
\hline $\mathbf{2 0 0 3}$ & 574 & 4894 & 7251 & 13891 & 496 & 5013 & 36 \\
\hline $\mathbf{2 0 0 4}$ & 710 & 5216 & 8281 & 15265 & 215 & 6104 & 31 \\
\hline $\mathbf{2 0 0 5}$ & 956 & 5789 & 9395 & 17950 & 250 & 7183 & 33 \\
\hline $\mathbf{2 0 0 6}$ & 1218 & 6408 & 10889 & 19944 & 273 & 7913 & 36 \\
\hline $\mathbf{2 0 0 7}$ & 1558 & 6961 & 12017 & 21842 & 306 & 8435 & 36 \\
\hline $\mathbf{2 0 0 8}$ & 1830 & 7627 & 13178 & 23773 & 330 & 9152 & 48 \\
\hline $\mathbf{2 0 0 9}$ & 2313 & 7975 & 14758 & 25796 & 370 & 10144 & 37 \\
\hline $\mathbf{2 0 1 0}$ & 2938 & 9077 & 16138 & 28876 & 408 & 10926 & 30 \\
\hline $\mathbf{2 0 1 1}$ & 3734 & 9712 & 18218 & 32866 & 455 & 12091 & 52 \\
\hline $\mathbf{2 0 1 2}$ & 4260 & 10242 & 19466 & 35638 & 508 & 13017 & 66 \\
\hline $\mathbf{2 0 1 3}$ & 5179 & 11587 & 22087 & 40315 & 516 & 14464 & 99 \\
\hline $\mathbf{2 0 1 4}$ & 5833 & 15473 & 52617 & 46544 & 850 & 15268 & 133 \\
\hline $\mathbf{2 0 1 5}$ & 6277 & 17834 & 23538 & 51619 & 787 & 15967 & 191 \\
\hline $\mathbf{2 0 1 6}$ & 6283 & 18114 & 23018 & 50883 & 860 & 15657 & 265 \\
\hline $\mathbf{2 0 1 7}$ & 6353 & 19502 & 23150 & 53128 & 901 & 16053 & 460 \\
\hline $\mathbf{2 0 1 8}$ & 6550 & 21028 & 23506 & 55602 & 816 & 16559 & 649 \\
\hline $\mathbf{2 0 1 9}$ & 7192 & 23027 & 25045 & 60777 & 912 & 17763 & 857 \\
\hline $\mathbf{2 0 2 0}$ & 7797 & 18590 & 26061 & 62086 & 1031 & 17510 & 1317 \\
\hline Summe & $\mathbf{7 2 3 5 3}$ & $\mathbf{2 2 8 3 7 0}$ & $\mathbf{3 3 1 7 4 3}$ & $\mathbf{6 8 2 9 4 2}$ & $\mathbf{1 1 1 0 2}$ & $\mathbf{2 2 8 6 8 4}$ & $\mathbf{4 4 3 0}$ \\
\hline & & & & & & & \\
\hline
\end{tabular}


b) Abbildung 16: Summe der internationalen Fachpublikationen (2001-2020)



Quelle: Siehe Indikatorenblatt 5B-04.

c) Abbildung 17: Internationale Fachpublikationen mit deutscher Autor*innenschaft (2001-2020)

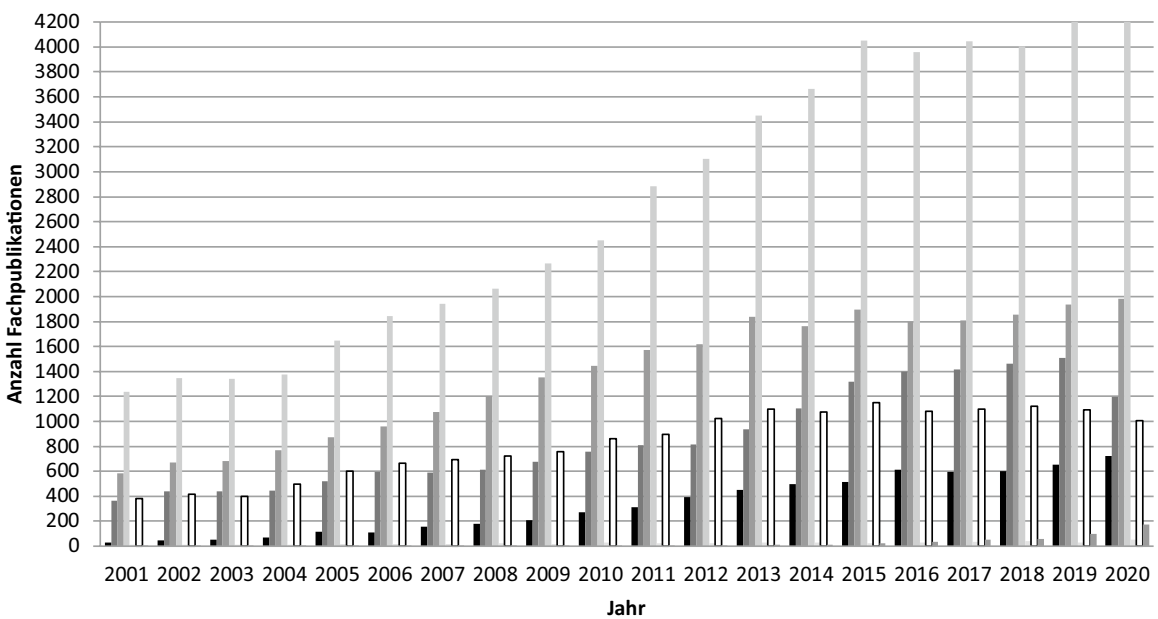

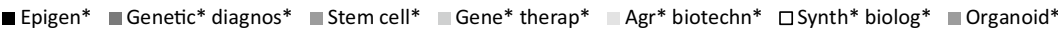
Quelle: Siehe Indikatorenblatt 5B-04. 


\begin{tabular}{|l|c|c|c|c|c|c|c|}
\hline Deutsch & Epigen* & $\begin{array}{l}\text { Gendiag- } \\
\text { nost* }^{*}\end{array}$ & $\begin{array}{l}\text { Stamm- } \\
\text { zell* }\end{array}$ & $\begin{array}{l}\text { Genthe- } \\
\text { rap* }\end{array}$ & $\begin{array}{l}\text { Grüne } \\
\text { Gentechn* }\end{array}$ & $\begin{array}{l}\text { Synth* } \\
\text { Biol* }^{*}\end{array}$ & $\begin{array}{l}\text { Orga- } \\
\text { noid* }^{*}\end{array}$ \\
\hline $\mathbf{2 0 0 1}$ & 29 & 363 & 582 & 1236 & 12 & 381 & 1 \\
\hline $\mathbf{2 0 0 2}$ & 45 & 439 & 668 & 1346 & 12 & 415 & 6 \\
\hline $\mathbf{2 0 0 3}$ & 50 & 441 & 682 & 1339 & 13 & 398 & 3 \\
\hline $\mathbf{2 0 0 4}$ & 50 & 441 & 682 & 1339 & 13 & 398 & 3 \\
\hline $\mathbf{2 0 0 5}$ & 115 & 522 & 873 & 1647 & 17 & 600 & 2 \\
\hline $\mathbf{2 0 0 6}$ & 108 & 596 & 959 & 1842 & 16 & 667 & 1 \\
\hline $\mathbf{2 0 0 7}$ & 157 & 592 & 1075 & 1941 & 16 & 693 & 3 \\
\hline $\mathbf{2 0 0 8}$ & 178 & 611 & 1204 & 2063 & 23 & 722 & 3 \\
\hline $\mathbf{2 0 0 9}$ & 209 & 675 & 1351 & 2265 & 17 & 758 & 2 \\
\hline $\mathbf{2 0 1 0}$ & 273 & 758 & 1447 & 2451 & 28 & 864 & 3 \\
\hline $\mathbf{2 0 1 1}$ & 311 & 812 & 1573 & 2882 & 26 & 895 & 3 \\
\hline $\mathbf{2 0 1 2}$ & 395 & 813 & 1621 & 3104 & 26 & 1023 & 1 \\
\hline $\mathbf{2 0 1 3}$ & 449 & 934 & 1837 & 3449 & 30 & 1101 & 10 \\
\hline $\mathbf{2 0 1 4}$ & 498 & 1104 & 1760 & 3666 & 30 & 1071 & 11 \\
\hline $\mathbf{2 0 1 5}$ & 514 & 1315 & 1896 & 4051 & 23 & 1148 & 26 \\
\hline $\mathbf{2 0 1 6}$ & 613 & 1400 & 1795 & 3960 & 31 & 1081 & 34 \\
\hline $\mathbf{2 0 1 7}$ & 593 & 1414 & 1807 & 4046 & 37 & 1101 & 53 \\
\hline $\mathbf{2 0 1 8}$ & 600 & 1464 & 1855 & 4006 & 40 & 1122 & 56 \\
\hline $\mathbf{2 0 1 9}$ & 654 & 1510 & 1936 & 4223 & 31 & 1092 & 96 \\
\hline $\mathbf{2 0 2 0}$ & 723 & 1198 & 1984 & 4311 & 53 & 1005 & 172 \\
\hline Summe & $\mathbf{6 5 8 5}$ & $\mathbf{1 7 4 0 7}$ & $\mathbf{2 7 6 7 5}$ & $\mathbf{5 5 2 0 1}$ & $\mathbf{4 9 5}$ & $\mathbf{1 6 6 3 5}$ & $\mathbf{4 8 9}$ \\
\hline
\end{tabular}

d) Abbildung 18: Summe der internationalen Fachpublikationen mit deutscher Autor*innenschaft (2001-2020)

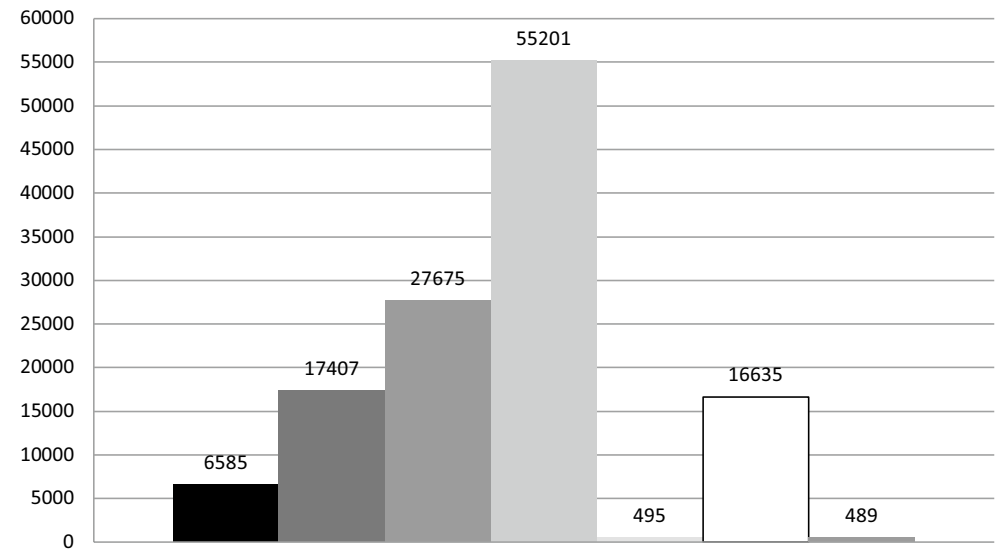

Summe der internationalen Fachpublikationen mit deutscher Autor*innenschaft (2001-2020)
- Epigen*
m Genetic* diagnos* " Stem cell*
Gene* therap*
Agr* biotechn*
口Synth* biolog* @ Organoid*

Quelle: Siehe Indikatorenblatt 5B-04. 
Laufende Nr.: 5B-05

Problemfeld: Realisierung Forschungsziele + Forschungsstandort Deutschland

\section{INDIKATOR: FÖRDERUNG DURCH DEN BUND ZU DEN THEMENDFELDERN DER IAG}

\section{DATENQUELLE:}

Datenbank Förderkatalog des Bundes. Unter: http://foerderportal.bund.de/foekat/

Zugriff: Januar 2021; Stand: 13.01.2021

\section{VERFÜGBARKEIT DER DATEN:}

Öffentlich.

In der Datenbank Förderkatalog des Bundes werden der Öffentlichkeit Informationen zu abgeschlossenen und laufenden Vorhaben der Projektförderung durch den Bund bereitgestellt. Der Datenbestand insgesamt umfasst mehr als 110.000 Förderungen. Die Datenbank enthält Vorhaben folgender Bundesministerien: Bundesministerium für Bildung und Forschung, Bundesministerium für Umwelt, Naturschutz und nukleare Sicherheit, Bundesministerium für Wirtschaft und Energie, Bundesministerium für Ernährung und Landwirtschaft, Bundesministerium für Verkehr und digitale Infrastruktur, Bundesministerium der Justiz und für Verbraucherschutz.

\section{ABGRENZUNG DER BERECHNUNGSGRÖSSEN:}

Die Daten stammen aus einer Datenbank-Recherche beim Förderkatalog des Bundes. In die Suchmasken der Vorhabensuche wurden in mehreren Schritten in der Schnellsuche die Stichwörter: \%Epigen\%, \%genet\% \%Diagnostik\%, $\%$ Stammzell\%, \%Gentherap $\%$, \%grüne $\% \%$ Gentechn $\%$, \%synthet $\%$ \%Biol\% und \%Organoid\% eingegeben. Suche anwenden auf: alle Vorhaben.

\section{GLIEDERUNG DER DARSTELLUNG:}

a) Fördersummen durch den Bund (2001-2022)

b) Gesamtfördersumme durch den Bund (2001-2022)

\section{BERECHNUNGSHÄUFIGKEIT:}

Jährlich.

\section{AUSSAGEFÄHIGKEIT:}

Der Indikator gibt Auskunft über die Höhe der Förderungen in den verschiedenen Bereichen der Gentechnologie durch den Bund. Die Datenbank Förderkatalog garantiert nach eigenen Angaben keine 100\%ige Abdeckung aller in den genannten Ministerien bewilligten Zuwendungsfällen, da jedes Ressort eigenverantwortlich entscheidet, welche Zuwendungsbereiche in den Förderkatalog gestellt werden. Die Darstellung ab 2021 ist unvollständig, da ab diesem Jahr noch Förderungen hinzu kommen können, die noch nicht in der Datenbank stehen. Die ab 2021 gelisteten Dateneinträge ergeben sich aus längeren Laufzeiten von Projekten, die bis 2020 im Förderkatalog eingetragen wurden. Es wurden auch Förderungen anteilig berücksichtigt, die vor 2001 begannen oder nach 2022 enden. 
a) Abbildung 19: Fördersummen durch den Bund (2001-2022)

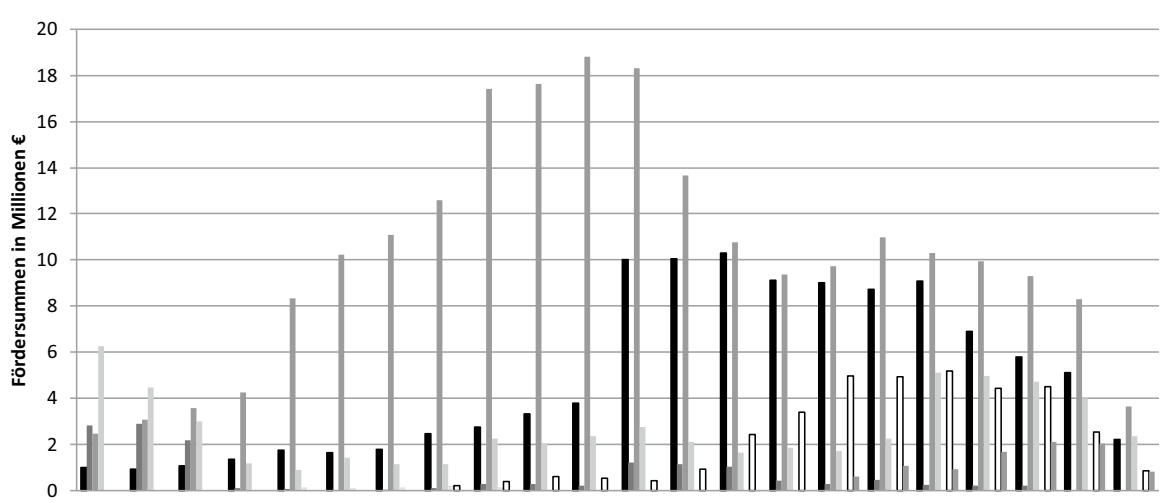

2001200220032004200520062007200820092010201120122013201420152016201720182019202020212022 Jahr

- $\%$ Epigen\%



\#Gentherap\%

\%grüne\% \%Gentechn\% $\square \%$ synthet\% \%Biol\% — \%Organoid\%

Die Daten ab 2021 sind unvollständig.

Quelle: Siehe Indikatorblatt 5B-05.

\begin{tabular}{|l|c|c|l|l|l|l|c|}
\hline & Epigen* & $\begin{array}{l}\text { Gendiag- } \\
\text { nost* }\end{array}$ & $\begin{array}{l}\text { Stamm- } \\
\text { zell* }\end{array}$ & $\begin{array}{l}\text { Genthe- } \\
\text { rap* }\end{array}$ & $\begin{array}{l}\text { Grüne } \\
\text { Gentechn* }\end{array}$ & $\begin{array}{l}\text { Synth* } \\
\text { Biol* }^{*}\end{array}$ & $\begin{array}{l}\text { Orga- } \\
\text { noid* }^{*}\end{array}$ \\
\hline $\mathbf{2 0 0 1}$ & 992298 & 2841754 & 2458572 & 6265421 & 0 & 0 & 0 \\
\hline $\mathbf{2 0 0 2}$ & 936099 & 2898837 & 3085330 & 4465809 & 0 & 0 & 0 \\
\hline $\mathbf{2 0 0 3}$ & 1066309 & 2193495 & 3582297 & 3006867 & 0 & 0 & 0 \\
\hline $\mathbf{2 0 0 4}$ & 1373270 & 109370 & 4245500 & 1177521 & 0 & 0 & 0 \\
\hline $\mathbf{2 0 0 5}$ & 1769742 & 66036 & 8335884 & 882182 & 148287 & 0 & 0 \\
\hline $\mathbf{2 0 0 6}$ & 1639532 & 0 & 10230524 & 1438213 & 107898 & 0 & 0 \\
\hline $\mathbf{2 0 0 7}$ & 1804774 & 44235 & 11082940 & 1158483 & 159505 & 0 & 0 \\
\hline $\mathbf{2 0 0 8}$ & 2485582 & 114235 & 12571002 & 1158483 & 214643 & 216284 & 0 \\
\hline $\mathbf{2 0 0 9}$ & 2764778 & 297522 & 17399876 & 2245703 & 134385 & 377247 & 0 \\
\hline $\mathbf{2 0 1 0}$ & 3325385 & 292531 & 17622914 & 2053200 & 39793 & 611654 & 0 \\
\hline $\mathbf{2 0 1 1}$ & 3801716 & 214140 & 18794926 & 2352537 & 39793 & 528388 & 0 \\
\hline $\mathbf{2 0 1 2}$ & 9996324 & 1230506 & 18319933 & 2765861 & 0 & 431106 & 0 \\
\hline $\mathbf{2 0 1 3}$ & 10060570 & 1132624 & 13675722 & 2094171 & 0 & 933377 & 0 \\
\hline $\mathbf{2 0 1 4}$ & 10304895 & 1028901 & 10752164 & 1648774 & 0 & 2442891 & 0 \\
\hline $\mathbf{2 0 1 5}$ & 9118296 & 416430 & 9359411 & 1870280 & 0 & 3380824 & 0 \\
\hline $\mathbf{2 0 1 6}$ & 9000160 & 290153 & 9721174 & 1726494 & 0 & 4956073 & 602732 \\
\hline $\mathbf{2 0 1 7}$ & 8743603 & 451353 & 10992844 & 2244819 & 0 & 4921885 & 1070270 \\
\hline $\mathbf{2 0 1 8}$ & 9077262 & 250567 & 10284388 & 5115641 & 0 & 5181564 & 923450 \\
\hline $\mathbf{2 0 1 9}$ & 6910854 & 229122 & 9955547 & 4954341 & 0 & 4424673 & 1680445 \\
\hline $\mathbf{2 0 2 0}$ & 5784558 & 229122 & 9290951 & 4704164 & 0 & 4496347 & 2094500 \\
\hline & & & & & & & \\
\hline
\end{tabular}




\begin{tabular}{|l|c|c|l|l|l|l|l|}
\hline & Epigen* & $\begin{array}{l}\text { Gendiag- } \\
\text { nost* }\end{array}$ & $\begin{array}{l}\text { Stamm- } \\
\text { zell* }\end{array}$ & $\begin{array}{l}\text { Genthe- } \\
\text { rap* }\end{array}$ & $\begin{array}{l}\text { Grüne } \\
\text { Gentechn* }\end{array}$ & $\begin{array}{l}\text { Synth* } \\
\text { Biol* }\end{array}$ & $\begin{array}{l}\text { Orga- } \\
\text { noid* }^{*}\end{array}$ \\
\hline $\mathbf{2 0 2 1}$ & 5112027 & 0 & 8279804 & 3998842 & 0 & 2548206 & 2049500 \\
\hline $\mathbf{2 0 2 2}$ & 2231441 & 0 & 3646488 & 2376752 & 0 & 860161 & 821709 \\
\hline Summe & $\mathbf{1 0 8 2 9 9 4 7 5}$ & $\mathbf{1 4 3 3 0 9 3 3}$ & $\mathbf{2 2 3 6 8 8 1 9 1}$ & $\mathbf{5 9 7 0 4 5 5 8}$ & $\mathbf{8 4 4 3 0 4}$ & $\mathbf{3 6 3 1 0 6 8 0}$ & $\mathbf{9 2 4 2 6 0 6}$ \\
\hline
\end{tabular}

b) Abbildung 20: Gesamtfördersumme durch den Bund (2001-2022)

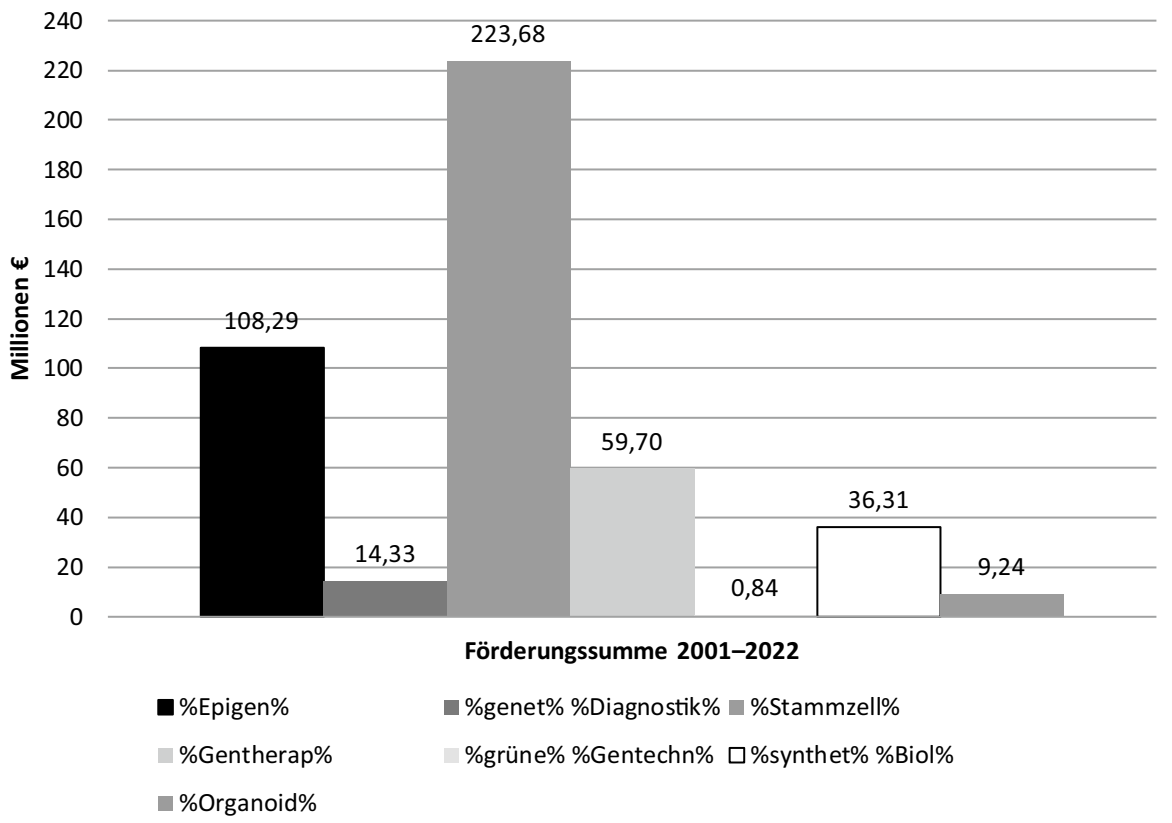

Die Daten ab 2021 sind unvollständig.

Quelle: Siehe Indikatorblatt 5B-05. 
Laufende Nr.: 5B-06

Problemfeld: Öffentliche Wahrnehmung + Soziale Implikationen + Dialogverpflichtung der Forschung + Ethische Implikationen

\section{INDIKATOR: ÖFFENTLICHE VERANSTALTUNGEN ZU DEN THEMENFELDERN DER IAG}

\section{DATENQUELLE:}

Informationsdienst Wissenschaft e. V. Unter: www.idw-online.de

Zugriff: Januar 2021; Stand: 11.01.2021

\section{VERFÜGBARKEIT DER DATEN:}

Öffentlich.

Der Informationsdienst Wissenschaft e. V. (idw) betreibt ein öffentlich zugängliches Internetportal für Pressemitteilungen und Veranstaltungsankündigungen von mehreren Hundert angeschlossenen wissenschaftlichen Einrichtungen, Vereinen und Unternehmen.

\section{ABGRENZUNG DER BERECHNUNGSGRÖSSEN:}

Für die Recherche wurden im idw-Archiv Veranstaltungen zu den Suchbegriffen „Epigen*", "Gendiagnost* ", "Stammzell ", "Gentherap*", "Grüne Gentechn*”, "Synth* Biol*" und "Organoid* recherchiert, die zwischen 2001 und 2020 stattgefunden haben. Die Trefferliste wurde anschließend für thematisch einschlägige Veranstaltungen händisch gefiltert, die sich gezielt an die Öffentlichkeit im Sinne interessierter Bürger*innen, der Politik, Entscheidungsträger*innen sowie an die Presse richteten. Geschlossene Fachtagungen oder englischsprachige Veranstaltungen wurden nicht aufgenommen. Mehrfache Ankündigungen einer Veranstaltung wurden zusammengefasst.

\section{GLIEDERUNG DER DARSTELLUNG:}

a) Anzahl an öffentlichen Veranstaltungen (2001-2020)

b) Summe der öffentlichen Veranstaltungen (2001-2020)

\section{BERECHNUNGSHÄUFIGKEIT:}

Jährlich.

\section{AUSSAGEFÄHIGKEIT:}

Öffentliche Veranstaltungen können als Indiz für die Kommunikationsbereitschaft der Forschungsgemeinschaft gesehen werden. Fachergebnisse der Öffentlichkeit allgemeinverständlich vorzustellen und mit ihr über die gesellschaftlichen Implikationen einer Gentechnologie zu diskutieren, stellt ein wichtiges Mittel der Wissenschaftskommunikation innerhalb der Gesellschaft dar. Neben der Wissenschaft werden weitere Interessengruppen aus Politik, Wirtschaft und Zivilgesellschaft sichtbar, die in einem Bereich der Gentechnologien den Dialog mit der Öffentlichkeit suchen. 
a) Abbildung 21: Anzahl an öffentlichen Veranstaltungen (2001-2020)



—Epigen* Gendiagnost* $\square$ Stammzell* $\backsim$ Gentherap* Grüne Gentechn* $\square$ Synth* Biol* $\square$ Organoid* Quelle: Siehe Indikatorenblatt 5B-06.

\begin{tabular}{|l|c|c|c|c|c|c|c|}
\hline & Epigen* & $\begin{array}{l}\text { Gendiag- } \\
\text { nost* }\end{array}$ & $\begin{array}{l}\text { Stamm- } \\
\text { zell* }\end{array}$ & $\begin{array}{l}\text { Genthe- } \\
\text { rap* }\end{array}$ & $\begin{array}{l}\text { Grüne } \\
\text { Gentechn* }\end{array}$ & $\begin{array}{l}\text { Synth* } \\
\text { Biol* }\end{array}$ & $\begin{array}{l}\text { Orga- } \\
\text { noid* }\end{array}$ \\
\hline $\mathbf{2 0 0 1}$ & 0 & 1 & 18 & 6 & 1 & 3 & 0 \\
\hline $\mathbf{2 0 0 2}$ & 7 & 1 & 9 & 7 & 3 & 1 & 0 \\
\hline $\mathbf{2 0 0 3}$ & 3 & 0 & 6 & 6 & 2 & 1 & 0 \\
\hline $\mathbf{2 0 0 4}$ & 0 & 1 & 7 & 1 & 2 & 0 & 0 \\
\hline $\mathbf{2 0 0 5}$ & 1 & 1 & 11 & 0 & 2 & 4 & 0 \\
\hline $\mathbf{2 0 0 6}$ & 1 & 3 & 29 & 1 & 4 & 6 & 0 \\
\hline $\mathbf{2 0 0 7}$ & 1 & 1 & 6 & 0 & 2 & 0 & 0 \\
\hline $\mathbf{2 0 0 8}$ & 2 & 0 & 12 & 3 & 1 & 4 & 0 \\
\hline $\mathbf{2 0 0 9}$ & 1 & 2 & 19 & 2 & 3 & 6 & 0 \\
\hline $\mathbf{2 0 1 0}$ & 7 & 4 & 17 & 1 & 7 & 8 & 0 \\
\hline $\mathbf{2 0 1 1}$ & 3 & 1 & 9 & 3 & 2 & 12 & 0 \\
\hline $\mathbf{2 0 1 2}$ & 5 & 1 & 8 & 3 & 1 & 8 & 0 \\
\hline $\mathbf{2 0 1 3}$ & 6 & 2 & 11 & 1 & 1 & 8 & 0 \\
\hline $\mathbf{2 0 1 4}$ & 4 & 0 & 10 & 1 & 1 & 6 & 0 \\
\hline $\mathbf{2 0 1 5}$ & 4 & 0 & 9 & 2 & 2 & 9 & 0 \\
\hline $\mathbf{2 0 1 6}$ & 1 & 0 & 19 & 2 & 0 & 5 & 0 \\
\hline
\end{tabular}




\begin{tabular}{|l|c|c|c|c|c|c|c|}
\hline & Epigen* & $\begin{array}{l}\text { Gendiag- } \\
\text { nost* }\end{array}$ & $\begin{array}{l}\text { Stamm- } \\
\text { zell* }\end{array}$ & $\begin{array}{l}\text { Genthe- } \\
\text { rap* }\end{array}$ & $\begin{array}{l}\text { Grüne } \\
\text { Gentechn* }\end{array}$ & $\begin{array}{l}\text { Synth* } \\
\text { Biol* }^{*}\end{array}$ & $\begin{array}{l}\text { Orga- } \\
\text { noid* }^{*}\end{array}$ \\
\hline $\mathbf{2 0 1 7}$ & 8 & 0 & 14 & 4 & 0 & 1 & 2 \\
\hline $\mathbf{2 0 1 8}$ & 5 & 0 & 6 & 3 & 0 & 12 & 2 \\
\hline $\mathbf{2 0 1 9}$ & 4 & 0 & 7 & 3 & 1 & 7 & 2 \\
\hline $\mathbf{2 0 2 0}$ & 3 & 0 & 2 & 1 & 0 & 6 & 2 \\
\hline Summe & $\mathbf{6 6}$ & $\mathbf{1 8}$ & $\mathbf{2 2 9}$ & $\mathbf{5 0}$ & $\mathbf{3 5}$ & $\mathbf{1 0 7}$ & $\mathbf{8}$ \\
\hline
\end{tabular}

b) Abbildung 22: Summe der öffentlichen Veranstaltungen (2001-2020)

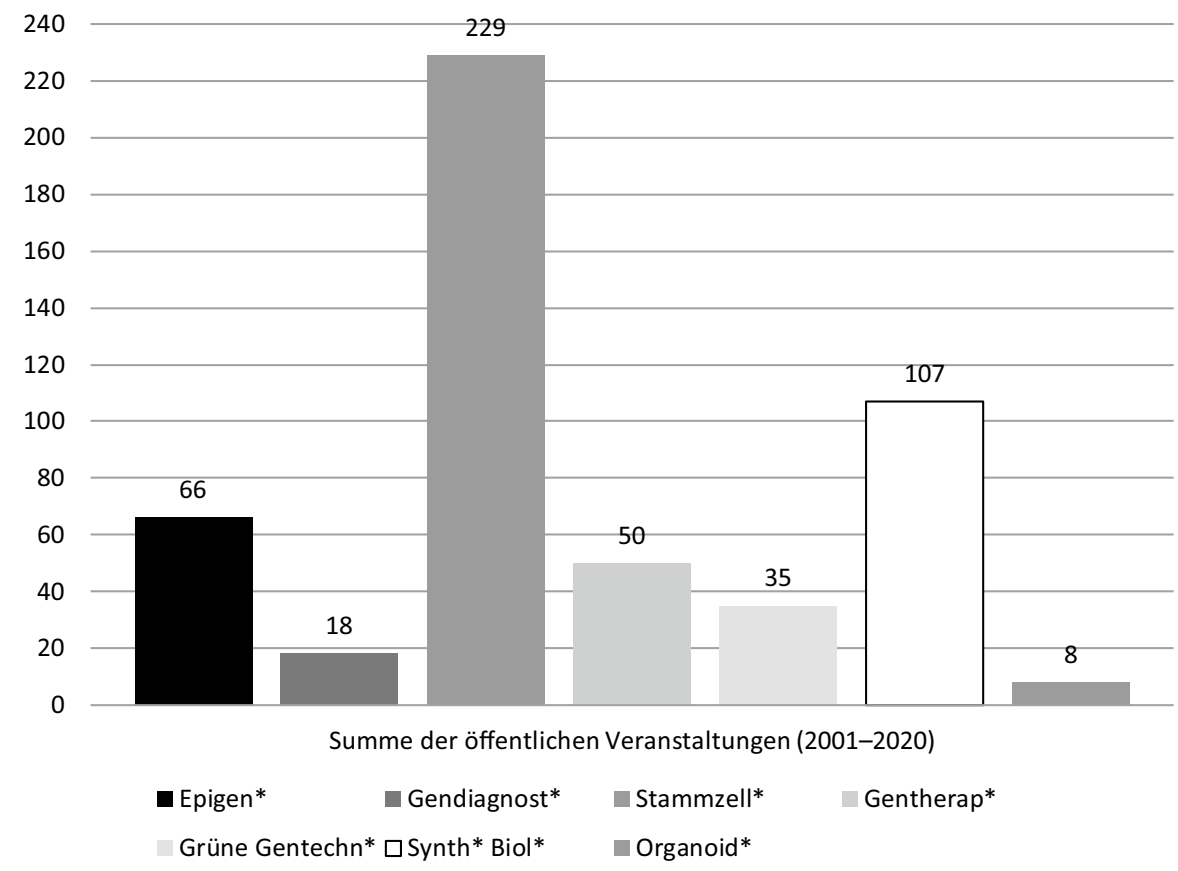

Quelle: Siehe Indikatorenblatt 5B-06. 
Laufende Nr.: 5B-07

Problemfeld: Realisierung Forschungsziele + Forschungsstandort Deutschland

\section{INDIKATOR: FÖRDERMASSNAHMEN DER DFG ZU DEN THEMENFELDERN DER IAG}

\section{DATENQUELLE:}

GEPRIS - Geförderte Projekte Informationssystem. Unter: http://gepris.dfg.de

Zugriff: Januar 2021, Stand: 11.01.2021

\section{VERFÜGBARKEIT DER DATEN:}

Öffentlich.

GEPRIS ist eine Internetplattform, die über die Fördermaßnahmen der Deutschen Forschungsgemeinschaft (DFG) informiert. Laut DFG sind hier Daten zu bewilligten Projekten aus allen DFG-Förderprogrammen seit dem 01.01.1999 aufgeführt. Die Datenbank wird fortlaufend aktualisiert. Der Zugang ist kostenlos. Es werden keine Fördersummen für einzelne Projekte in GEPRIS ausgewiesen.

\section{ABGRENZUNG DER BERECHNUNGSGRÖSSEN:}

Für die Recherche relevanter DFG-geförderter Projekte wurden die Stichworte "Epigen*”, "Gendiagnos*", "Stammzell*”, "Gentherap*", "Grüne* Gentechn*”, "Synth* Biol*" und "Organoid* " verwendet ( „Erweiterte Suche" in „Projekte", exkl. geförderter Teilprojekte, inkl. Projekte ohne Abschlussbericht). Es wurde keine weiterführende qualitative Filterung der Suchergebnisse vorgenommen. Es wurden alle abgeschlossenen und laufenden Projekte ab 2001 (Beginn der IAG Gentechnologiebericht) bis 2020 (abgeschlossenes Kalenderjahr) recherchiert. Ein direkter Vergleich zwischen den Themen ist nur bedingt möglich, da die Themen von den Suchbegriffen unterschiedlich gut abgedeckt werden. Insbesondere Projekte zur "Grünen Gentechnologie" lassen sich nur schlecht recherchieren. Abweichungen der Daten (im Vergleich zu früheren Erhebungen des Indikators) können aufgrund von Änderungen der Beschreibungstexte, späterem Einfügen von Daten oder Änderungen des Suchalgorithmus entstehen.

\section{GLIEDERUNG DER DARSTELLUNG:}

a) Anzahl an DFG-geförderten Projekten (2001-2020)

b) Summe der DFG-geförderten Projekte (2001-2020)

c) Anzahl an pro Jahr beginnenden DFG-geförderten Projekten (2001-2020)

d) Summe der begonnenen DFG-Förderungen (2001-2020)

\section{BERECHNUNGSHÄUFIGKEIT:}

Jährlich.

\section{AUSSAGEFÄHIGKEIT:}

Die Deutsche Forschungsgemeinschaft (DFG) versteht sich als Selbstverwaltungsorgan der deutschen Forschung. Sie stellt eine wichtige Fördereinrichtung für die Wissenschaft in Deutschland dar - vor allem in Hinblick auf den stetig zunehmenden Stellenwert der Einwerbung von Drittmitteln an Hochschulen und außeruniversitären Forschungsinstituten. Das Ausmaß der DFG-Förderung erlaubt Rückschlüsse auf das wissenschaftliche und wirtschaftliche Potenzial des Feldes. Für eine umfassende Beurteilung ist eine langfristige Beobachtung angezeigt. Zudem sind in diesem Zusammenhang weitere Quellen der Finanzierung zu berücksichtigen. Die Summe der begonnenen Förderungen gibt Aufschluss über die Anzahl durchgeführter Vorhaben, sagt jedoch nichts darüber aus, ob diese Vorhaben noch laufen oder bereits abgeschlossen sind. 
a) Abbildung 23: Anzahl an DFG-geförderten Projekten (2001-2020)



Quelle: Siehe Indikatorblatt 5B-07.

\begin{tabular}{|l|c|c|c|c|c|c|c|c|}
\hline & Epigen* & $\begin{array}{l}\text { Gendiag- } \\
\text { nost* }\end{array}$ & $\begin{array}{l}\text { Stamm- } \\
\text { zell* }\end{array}$ & $\begin{array}{l}\text { Genthe- } \\
\text { rap* }^{*}\end{array}$ & $\begin{array}{l}\text { Grüne } \\
\text { Gentechn* }\end{array}$ & $\begin{array}{l}\text { Synth* } \\
\text { Biol* }^{*}\end{array}$ & $\begin{array}{l}\text { Orga- } \\
\text { noid* }\end{array}$ & $\begin{array}{l}\text { pro } \\
\text { Jahr }\end{array}$ \\
\hline $\mathbf{2 0 0 1}$ & 21 & 1 & 96 & 97 & 1 & 222 & 0 & 438 \\
\hline $\mathbf{2 0 0 2}$ & 31 & 1 & 122 & 110 & 1 & 284 & 0 & 549 \\
\hline $\mathbf{2 0 0 3}$ & 42 & 2 & 132 & 96 & 1 & 332 & 0 & 605 \\
\hline $\mathbf{2 0 0 4}$ & 55 & 2 & 158 & 85 & 2 & 402 & 0 & 704 \\
\hline $\mathbf{2 0 0 5}$ & 80 & 2 & 168 & 83 & 2 & 492 & 0 & 827 \\
\hline $\mathbf{2 0 0 6}$ & 111 & 2 & 206 & 87 & 3 & 572 & 0 & 981 \\
\hline $\mathbf{2 0 0 7}$ & 137 & 2 & 235 & 79 & 5 & 693 & 0 & 1151 \\
\hline $\mathbf{2 0 0 8}$ & 160 & 3 & 255 & 66 & 5 & 730 & 0 & 1219 \\
\hline $\mathbf{2 0 0 9}$ & 182 & 3 & 260 & 53 & 4 & 738 & 4 & 1244 \\
\hline $\mathbf{2 0 1 0}$ & 202 & 1 & 294 & 41 & 3 & 783 & 5 & 1329 \\
\hline $\mathbf{2 0 1 1}$ & 208 & 0 & 290 & 39 & 1 & 731 & 7 & 1276 \\
\hline $\mathbf{2 0 1 2}$ & 223 & 0 & 299 & 39 & 0 & 675 & 12 & 1248 \\
\hline $\mathbf{2 0 1 3}$ & 236 & 0 & 327 & 33 & 0 & 679 & 12 & 1287 \\
\hline $\mathbf{2 0 1 4}$ & 264 & 0 & 355 & 37 & 0 & 683 & 21 & 1360 \\
\hline $\mathbf{2 0 1 5}$ & 277 & 0 & 359 & 38 & 0 & 633 & 22 & 1329 \\
\hline $\mathbf{2 0 1 6}$ & 271 & 1 & 377 & 36 & 0 & 586 & 28 & 1299 \\
\hline $\mathbf{2 0 1 7}$ & 279 & 1 & 421 & 34 & 0 & 535 & 41 & 1311 \\
\hline $\mathbf{2 0 1 8}$ & 295 & 1 & 440 & 38 & 0 & 493 & 47 & 1314 \\
\hline $\mathbf{2 0 1 9}$ & 312 & 1 & 446 & 40 & 0 & 444 & 61 & 1304 \\
\hline $\mathbf{2 0 2 0}$ & 347 & 1 & 431 & 35 & 0 & 399 & 74 & 1287 \\
\hline $\mathbf{S u m m e}$ & $\mathbf{3 7 3 3}$ & $\mathbf{2 4}$ & $\mathbf{5 6 7 1}$ & $\mathbf{1 1 6 6}$ & $\mathbf{2 8}$ & $\mathbf{1 1 1 0 6}$ & $\mathbf{3 3 4}$ & $\mathbf{2 2 0 6 2}$ \\
\hline
\end{tabular}


b) Abbildung 24: Summe der DFG-geförderten Projekte (2001-2020)



- Summe der Förderungen

Quelle: Siehe Indikatorblatt 5B-07.

c) Abbildung 25: Anzahl an pro Jahr beginnenden DFG-geförderten Projekten (2001-2020)

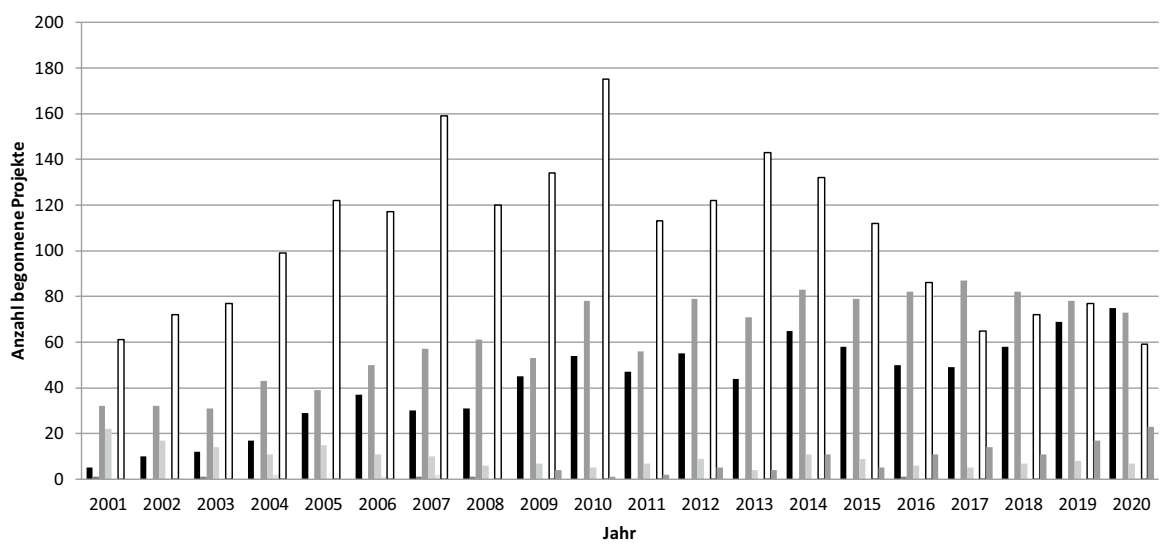

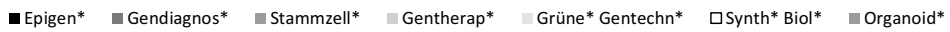

Quelle: Siehe Indikatorblatt 5B-07. 


\begin{tabular}{|l|c|c|c|c|c|c|c|}
\hline & Epigen & $\begin{array}{l}\text { Gendiag- } \\
\text { nost* }^{*}\end{array}$ & $\begin{array}{l}\text { Stamm- } \\
\text { zell* }\end{array}$ & $\begin{array}{l}\text { Genthe- } \\
\text { rap* }\end{array}$ & $\begin{array}{l}\text { Grüne } \\
\text { Gentechn* }\end{array}$ & $\begin{array}{l}\text { Synth* } \\
\text { Biol }^{*}\end{array}$ & $\begin{array}{l}\text { Orga- } \\
\text { noid* }^{*}\end{array}$ \\
\hline $\mathbf{2 0 0 1}$ & 5 & 1 & 32 & 22 & 0 & 61 & 0 \\
\hline $\mathbf{2 0 0 2}$ & 10 & 0 & 32 & 17 & 0 & 72 & 0 \\
\hline $\mathbf{2 0 0 3}$ & 12 & 1 & 31 & 14 & 0 & 77 & 0 \\
\hline $\mathbf{2 0 0 4}$ & 17 & 0 & 43 & 11 & 2 & 99 & 0 \\
\hline $\mathbf{2 0 0 5}$ & 29 & 0 & 39 & 15 & 0 & 122 & 0 \\
\hline $\mathbf{2 0 0 6}$ & 37 & 0 & 50 & 11 & 1 & 117 & 0 \\
\hline $\mathbf{2 0 0 7}$ & 30 & 1 & 57 & 10 & 2 & 159 & 0 \\
\hline $\mathbf{2 0 0 8}$ & 31 & 1 & 61 & 6 & 0 & 120 & 0 \\
\hline $\mathbf{2 0 0 9}$ & 45 & 0 & 53 & 7 & 0 & 134 & 4 \\
\hline $\mathbf{2 0 1 0}$ & 54 & 0 & 78 & 5 & 0 & 175 & 1 \\
\hline $\mathbf{2 0 1 1}$ & 47 & 0 & 56 & 7 & 0 & 113 & 2 \\
\hline $\mathbf{2 0 1 2}$ & 55 & 0 & 79 & 9 & 0 & 122 & 5 \\
\hline $\mathbf{2 0 1 3}$ & 44 & 0 & 71 & 4 & 0 & 143 & 4 \\
\hline $\mathbf{2 0 1 4}$ & 65 & 0 & 83 & 11 & 0 & 132 & 11 \\
\hline $\mathbf{2 0 1 5}$ & 58 & 0 & 79 & 9 & 0 & 112 & 5 \\
\hline $\mathbf{2 0 1 6}$ & 50 & 1 & 82 & 6 & 0 & 86 & 11 \\
\hline $\mathbf{2 0 1 7}$ & 49 & 0 & 87 & 5 & 0 & 65 & 14 \\
\hline $\mathbf{2 0 1 8}$ & 58 & 0 & 82 & 7 & 0 & 72 & 11 \\
\hline $\mathbf{2 0 1 9}$ & 69 & 0 & 78 & 8 & 0 & 77 & 17 \\
\hline $\mathbf{2 0 2 0}$ & 75 & 0 & 73 & 7 & 0 & 59 & 23 \\
\hline Summe & $\mathbf{8 4 0}$ & $\mathbf{5}$ & $\mathbf{1 2 4 6}$ & $\mathbf{1 9 1}$ & $\mathbf{5}$ & $\mathbf{2 1 1 7}$ & $\mathbf{1 0 8}$ \\
\hline
\end{tabular}

d) Abbildung 26: Summe der begonnenen DFG-Förderungen (2001-2020)

2500

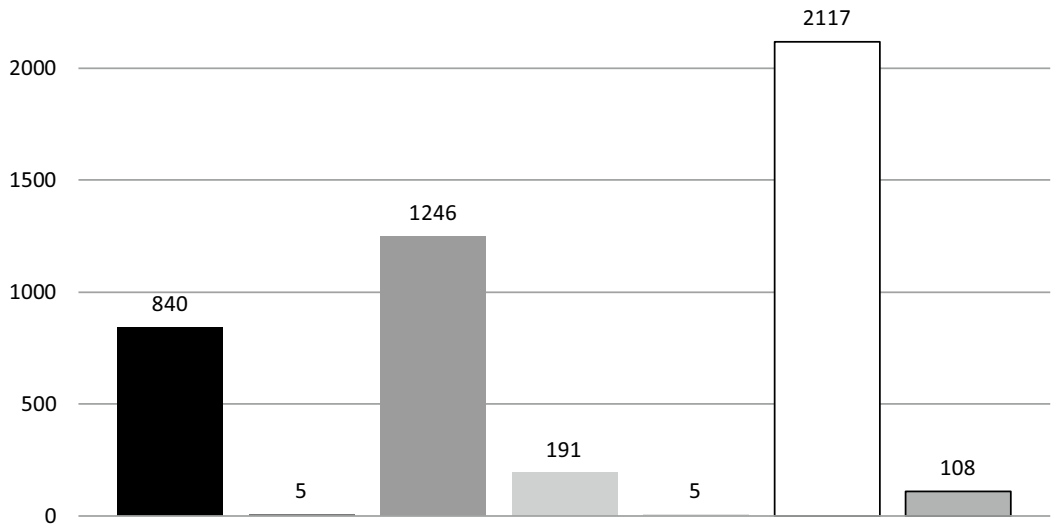

Summe der begonnenen Förderungen 2001-2019

-Epigen* Gendiagnos* ${ }^{*}$ Stammzell* Gentherap*

Grüne* Gentechn* $\square$ Synth* Biol* $\quad$ OOrganoid*

Quelle: Siehe Indikatorblatt 5B-07. 
Laufende Nr.: 5B-08

Problemfeld: Realisierung Forschungsziele + Forschungsstandort Deutschland

INDIKATOR: EU-FÖRDERMASSNAHMEN MIT AUSGEWIESENER DEUTSCHER BETEILIGUNG ZU DEN THEMENFELDERN DER IAG

\section{DATENQUELLE:}

CORDIS - Forschungs- und Entwicklungsinformationsdienst der Gemeinschaft.

Unter: http://cordis.europa.eu/projects/home_de.html

Zugriff: Januar 2021, Stand: 13.01.2020

\section{VERFÜGBARKEIT DER DATEN:}

\section{Öffentlich.}

CORDIS ist eine Internetplattform, die über die Fördermaßnahmen der Europäischen Union (EU) im Bereich Forschung und Entwicklung informiert. Es ist die wichtigste Informationsquelle für EU-finanzierte Projekte seit 1990. Der Zugang ist kostenlos. Über CORDIS werden u. a. die aktuellen Rahmenprogramme für Forschung und technologische Entwicklung der EU umgesetzt.

\section{ABGRENZUNG DER BERECHNUNGSGRÖSSEN:}

Für die Recherche, relevanter EU-geförderter Projekte, wurden die Stichworte „Epigenetic”, "Genetic Diagnosis", "Stem Cell", "Gene Therapy", "Agricultural Biotechnology", "Synthetic Biology" und "Organoid" in der CORDIS-Datenbank gesucht. An dieser Stelle ist anzumerken, dass die Stichwortsuche im Vergleich zum vierten Gentechnologiebericht angepasst werden musste, da durch eine Aktualisierung der CORDIS-Datenbank keine flächendeckende Suche mit Tunkierungen mehr möglich ist. Weiterhin wurde eine erweiterte Abfrage der Stichworte durchgeführt. Es wurden nur Suchergebnisse berücksichtigt, die Deutschland als Land der Organisation (Koordinator bzw. Teilnehmer) ausweisen. Es wurde keine weiterführende qualitative Filterung der Suchergebnisse vorgenommen. Die Suche wurde auf das 6. (2002-2007) und 7. (2007-2013) Forschungsrahmenprogramm der EU sowie auf deren Nachfolgerprogramm Horizon 2020 (2014-2020) beschränkt, die die gegenwärtige Laufzeit der IAG Gentechnologiebericht abdecken. Dabei ist zu beachten, dass Projekte möglicherweise anders verschlagwortet wurden und mit den verwendeten Suchbegriffen nicht auffindbar waren. Dies ist für die Themen Synthetische Biologie, Gendiagnostik und Grüne Gentechnologie besonders relevant. Abweichungen der Daten (im Vergleich zu früheren Erhebungen des Indikators) können aufgrund von Änderungen des Suchalgorithmus bzw. der Stichwortsuche entstehen.

\section{GLIEDERUNG DER DARSTELLUNG:}

a) Anzahl EU-geförderter Forschungsprojekte in FP6/FP7/Horizon 2020

\section{BERECHNUNGSHÄUFIGKEIT:}

Jährlich.

\section{AUSSAGEFÄHIGKEIT:}

Die EU-Forschungsrahmenprogramme können als wichtigstes Instrument der EU zur Förderung von Forschungs- und Entwicklungsmaßnahmen verstanden werden. Das Ausmaß der Forschungsförderung durch die EU erlaubt Rückschlüsse auf das wissenschaftliche und wirtschaftliche Potenzial der Gentechnologien, die auf europäischer Ebene angesiedelt sind. Zu einer umfassenden Beurteilung ist eine langfristige Beobachtung angezeigt. Zudem sind in diesem Zusammenhang weitere Quellen der öffentlichen Finanzierung zu berücksichtigen. 
a) Abbildung 27: Anzahl EU-geförderter Forschungsprojekte in FP6/FP7/Horizon 2020



Quelle: Siehe Indikatorblatt 5B-08.

\subsection{Indikatoren im Bereich der Gentechnologien: ein Überblick}

Schaut man sich die Indikatoren aus der Perspektive der einzelnen Themenbereiche Epigenetik, Stammzellforschung, Gendiagnostik, Gentherapie, Grüne Gentechnologie sowie synthetische Biologie und Organoidforschung an, lassen sich folgende Ergebnisse und Tendenzen erkennen. Erhoben wurden die Indikatoren themenspezifisch für den Zeitraum 2001 - dem Beginn der Arbeit der IAG Gentechnologiebericht - bis Dezember 2020.

Mediale Abbildung der Themenfelder der IAG (5B-01)

Für den Bereich der Stammzellforschung wurden mit Abstand die meisten Printartikel veröffentlicht (gesamt: 6.345; Peaks in den Jahren 2001 [1.291] und 2002 [845]). Nur für den Themenkomplex Grüne Gentechnologie liegt auch eine Vielzahl von Printartikeln vor (gesamt: 1.779). Niedrige Werte gibt es im Bereich der Organoidforschung, als noch junges Forschungsfeld (gesamt: 42). In absteigender Reihenfolge sind die Themen synthetische Biologie (gesamt: 1.151), Gentherapie (gesamt: 841), Epigenetik (gesamt: 573) sowie die Gendiagnostik (gesamt: 373) zu nennen. Bei den Onlineartikeln zeigt sich ein ähnliches Bild. Hohe Werte erreicht das Thema Stammzellforschung (gesamt: 1.451), 
gefolgt von der Grünen Gentechnologie mit 694 Artikeln. Auch hier gibt es im Bereich der Organoidforschung die wenigsten Berichte (gesamt: 52; eine erste Berichterstattung fand in den untersuchten Medien erst im Jahr 2013 statt). Niedrige Werte haben die folgenden Themen im Zeitverlauf 2001 bis 2020: Epigenetik (1-17), Gendiagnostik (1-20), Gentherapie (1-35) und synthetische Biologie (3-45).

Bei den Printartikeln fällt auf, dass die Stammzellforschung mit sehr vielen Publikationen beginnt (1.291 im Jahr 2001), deren Anzahl jedoch im Zeitverlauf ab ca. 2010 deutlich abnimmt und dann bei Werten um die 100 Publikationen stagniert. Bei den Onlineartikeln schwanken die Werte hingegen über den gesamten Zeitverlauf, mit einem Höchstwert von 137 im Jahr 2008 und einem Tiefstwert von 26 im Jahr 2003. Betrachtet man alle Themen gemeinsam, erkennt man eine relative Zunahme von Onlineberichten im Vergleich zu Printberichten, wobei die absoluten Zahlen der Printberichte höher liegen. Bei der synthetischen Biologie und der Epigenetik nimmt die Anzahl der Onlineartikel ab dem Jahr 2009 zu (auf max. 45 bzw. 17 Publikationen), während sie bei den Printartikeln stagniert (bei max. 75 bzw. 72 Beiträgen). Die Gendiagnostik ist in Printartikeln schwankend mit zwischen 4 und 54 Artikeln vertreten, bei den Onlineartikeln gab es 2012 einen Peak von 20 Beiträgen. Die Gentherapie schwankt zwischen 142 Printartikeln in 2001 und $8 \mathrm{im}$ Jahr 2011. Bei den Onlineartikeln sind es 1 bis 35 Artikel. Die Grüne Gentechnik hat einen Peak von 190 Printartikeln in 2009 und 22 Artikeln in 2019. Online sind es mindestens 16 Artikel (2003) und 94 Artikel (2009). Über Organoide wird in Deutschland erst seit 2013 online berichtet (zwischen 0 und 21 Artikel). In diesem Jahr begann auch die Printberichterstattung, hier schwanken die Werte zwischen 0 und 17, sodass die Printberichterstattung in etwa der Onlineberichterstattung gleicht. Schaut man sich die Entwicklung der Publikationszahlen für alle Themenbereiche im Zeitverlauf an, lässt sich feststellen, dass die Anzahl der Printartikel tendenziell abnimmt; bei den Onlineartikeln ist die Anzahl sehr schwankend (mit den Peaks in den Jahren 2009 und 2014).

Neuerscheinungen zu den Themenfeldern der IAG (5B-02)

Bei der Recherche der Neuerscheinungen, die von der Deutschen Nationalbibliothek erfasst werden, liegt - wie im Indikatorenblatt näher beschrieben - ein Fokus auf populärwissenschaftlichen bzw. an die breite Öffentlichkeit adressierten Publikationen. Die höchste Anzahl insgesamt gibt es nach wie vor im Bereich der Stammzellforschung (gesamt: 577; Peaks in den Jahren 2011 und 2017 [je 47]). Gefolgt wird dieser von den Themen Epigenetik (gesamt: 117) und Gendiagnostik (gesamt: 114, 0 bis 20 jährlich, zwischen 3 und 8 pro Jahr). Ähnliche Publikationszahlen weisen die Bereiche Grüne Gentechnologie (0 bis 10 ), Gentherapie (2 bis 8 ) sowie synthetische Biologie (0 bis 14) auf. Die wenigsten Veröffentlichungen existieren auf dem noch jungen Feld der Organoidforschung (insgesamt 6). 
Online-Suchanfragen zu den Themenfeldern der IAG (5B-03)

Der Indikator Onlinesuchanfragen beschreibt lediglich die relativen Suchhäufigkeiten. Deswegen ist ein direkter Vergleich der Auswertungen der verschiedenen Themenfelder nicht möglich. Festzustellen ist aber, dass die relative Nachfrage in den Bereichen Gendiagnostik, Stammzellforschung, Gentherapie sowie Grüne Gentechnologie hoch beginnt, dann aber im Zeitverlauf tendenziell sinkt; bei der synthetischen Biologie verhält es sich ähnlich; sinkt aber nicht ganz so stark. Auf dem Feld der Epigenetik und der Organoidforschung verhält es sich umgekehrt.

\section{Anzahl internationaler Fachartikel zu den Themenfeldern der IAG (5B-04)}

Die höchste Anzahl internationaler Fachartikel gibt es im Bereich der Gentherapie (gesamt: 682.942; Höchststand 2020: 62.089). Die Anzahl beginnt schon auf hohem Niveau (12.541 im Jahr 2001) und steigert sich kontinuierlich bis auf $62.089 \mathrm{im} \mathrm{Jahr} \mathrm{2020.} \mathrm{Hierbei}$ ist jedoch zu beachten, dass die Verwendung eines Suchbegriffs für ein Thema auch immer das Risiko birgt, nicht alle Publikationen erfassen zu können. Die Stammzellforschung hat mit insgesamt 331.743 Artikeln (Peak in 2020: 26.061) die zweithöchste Publikationszahl zu verzeichnen und auch hier steigen die Werte im Zeitverlauf an. Mittlere Werte liegen für die Themen Gendiagnostik (gesamt: 228.370) und synthetische Biologie (gesamt: 228.684) vor, bei leichten Zuwächsen im Zeitverlauf. Mit Blick auf die Anzahl folgen nun die Bereiche Epigenetik (gesamt: 72.353), Grüne Gentechnologie (gesamt: 11.102) und Organoidforschung (gesamt: 4.430). Hinsichtlich der Grünen Gentechnologie ist anzumerken, dass mit dem verwendeten Suchbegriff Agr* biotechn* eventuell nicht alle relevanten Veröffentlichungen erfasst werden konnten. Der Anteil der Fachpublikationen mit deutscher Autor*innenschaft spiegelt einen ähnlichen Verlauf wider; allerdings - wie zu erwarten - auf einem geringeren Niveau (Zahlen gesamt: Gentherapie: 55.201; Stammzellforschung: 27.675; Gendiagnostik: 17.407; synthetische Biologie: 16.635; Epigenetik: 6.585; Grüne Gentechnologie: 495; Organoidforschung: 489).

Förderung durch den Bund zu den Themenfeldern der IAG (5B-05)

Die Stammzellforschung liegt bei der Förderung durch den Bund mit rund 19 Mio. Euro im Jahr 2011 an erster Stelle. Die Epigenetik wird auch umfangreich gefördert: von 2005 bis 2014 stieg die Förderung stark an, von ca. 1 Mio. Euro auf über 10 Mio. Euro; seitdem sinkt sie allerdings wieder auf ca. 6 Mio. Euro in 2020. ${ }^{9}$ Die Forschungsförderung zur Gentherapie liegt im mittleren Bereich mit einem Peak im Jahr 2018 mit über 5 Mio. Euro; auch die synthetische Biologie ist hier zu verorten mit der höchsten För-

Die Zahlen ab 2020 sind unvollständig. 
derung im Jahr 2018 (ca. 5,1 Mio. Euro). Die Forschung zu Gendiagnostik und Organoiden wird im Vergleich dazu eher weniger unterstützt, wobei anzumerken ist, dass die Organoidforschung erst seit kurzem finanzielle Mittel erhielt und seitdem tendenziell ansteigt (Peak aktuell im Jahr 2020: 2,1 Mio. Euro). Die Grüne Gentechnologie erhält die niedrigste Förderung: Dieses Ergebnis kann aber auch darauf zurückzuführen sein, dass das Themenfeld mit dem verwendeten Suchbegriff nicht so gut zu erfassen ist.

In der Zusammenschau für die Jahre 2001 bis 2020 ist zu erkennen, dass die Stammzellforschung hinsichtlich der Förderung durch den Bund mit rund 224 Mio. Euro an der Spitze liegt. Die Epigenetik wird mit etwa 108 Mio. Euro gefördert und liegt somit an zweiter Stelle, gefolgt von der Gentherapie (ca. 60 Mio. Euro), der synthetischen Biologie (ca. 36 Mio. Euro), Gendiagnostik (ca. 14 Mio. Euro), der Organoidforschung (ca. 9 Mio. Euro) und der Grünen Gentechnologie (ca. 0,8 Mio. Euro).

\section{Öffentliche Veranstaltungen zu den Themenfeldern der IAG (5B-06)}

Bei den öffentlichen Veranstaltungen in Deutschland zu den unterschiedlichen Themenfeldern gibt es im Zeitverlauf kein Thema, das durchgehend im Vordergrund steht. Die Veranstaltungen wurden anhand der Eintragungen im IDW (Informationsdienst Wissenschaft e.V.) ${ }^{10}$ erfasst. Es ist festzustellen, dass die meisten Veranstaltungen zum Thema Stammzellforschung stattfanden; hier gab es z. B. 29 Veranstaltungen im Jahr 2006. Die synthetische Biologie stand im Mittelpunkt verschiedener Veranstaltungen in den Jahren 2011 sowie 2018 (je 12) und war somit in diesen Jahren Spitzenreiter. Die Epigenetik war im Jahr 2017 Thema bei 8, die Gentherapie 2001 und 2003 bei 6 Formaten. Wenige Veranstaltungen gab es zu den Bereichen Grüne Gentechnologie (Peak im Jahr 2010: 7), Gendiagnostik (1-4) und Organoidforschung (hier gibt es seit 2017 insgesamt erst 8 Veranstaltungen).

Fördermaßnahmen der DFG zu den Themenfeldern der IAG (5B-07)

Auffällig ist, dass vor allem Forschungen auf dem Gebiet der Stammzellforschung (im Jahr 2019: 446 Projekte; von 2001 bis 2020: insgesamt 1.246) und der synthetischen Biologie (im Jahr 2010: 783; 2001 bis 2020: 2.117) gefördert worden sind. Es folgt die Forschung zur Epigenetik mit insgesamt 840 begonnenen Projekten von 2001 bis 2020; die Förderung steigt im Zeitverlauf stetig an. Weniger gefördert werden die Gentherapie und die Organoidforschung: Erstere mit 191 gestarteten Projekten von 2001 bis 2020; im Bereich der Organoidforschung gibt es von 2009 bis 2020108 begonnene Projekte. Kaum gefördert werden die Bereiche Gendiagnostik und Grüne Gentechnologie. Dies

10 Siehe unter: www.idw-online.de [19.05.2021]. 
kann allerdings auf die Struktur der Datenbank GEPRIS und die dort verwendete Verschlagwortung zurückzuführen sein.

Für die Epigenetik lässt sich ein stetiger Anstieg der geförderten Projekte von $21 \mathrm{im}$ Jahr 2001 bis 347 im Jahr 2020 feststellen. Dies gilt auch für die Stammzellforschung mit 96 Projekten in 2001 und 446 in 2019. ${ }^{11}$ Forschungsprojekte zur Gendiagnostik und zur Grünen Gentechnologie konnten kaum gefunden werden. Organoidprojekte werden seit 2009 gefördert, wenn auch auf geringem Niveau. Die Förderung stieg von $4 \mathrm{im} \mathrm{Jahr}$ 2009 auf 74 im Jahr 2020. Die Gentherapie wurde auch kontinuierlich gefördert, ihre Werte liegen jedoch anfangs relativ hoch bei 97 Projekten in 2001, sinken dann auf 33 im Jahr 2013 und pendeln sich auf diesem Niveau ein. Spitzenreiter ist die synthetische Biologie mit 222 Projekten in 2001 und einem Höchststand von 783 Projekten in 2010. Danach fällt die Zahl wieder ab auf immer noch hohe 399 Projekte im Jahr 2020. Die Gesamtförderung aller sieben Themenbereiche stieg bis 2010 stetig an; danach sank diese und nahm ab dem Jahr 2013 wieder zu; ab 2015 war die Fördersumme wieder geringer, blieb dann aber in etwa auf konstantem Niveau.

EU-Fördermaßnahmen mit ausgewiesener deutscher Beteiligung zu den Themenfeldern der IAG (5B-08)

Wirft man einen Blick auf die EU-Fördermaßnahmen mit ausgewiesener deutscher Beteiligung, ist anzumerken, dass Projekte im Bereich der Stammzellforschung den größten Anteil mit 362 Projekten ausmachen; gefolgt von Projekten zur Epigenetik (183), synthetischen Biologie (119), Gentherapie (77), Organoidforschung (37) sowie zur Grünen Gentechnologie und Gendiagnostik mit je fünf Projekten.

\subsection{Literaturverzeichnis}

Bartfeld, S. et al. (2020): Organoide. Ihre Bedeutung für Forschung, Medizin und Gesellschaft. Nomos, Baden-Baden.

Diekämper, J./Hümpel, A. (2012): Daten zu ausgewählten Indikatoren. In: Köchy, K./Hümpel, A. (Hrsg.): Synthetische Biologie. Entwicklung einer neuen Ingenieurbiologie? Forum W, Dornburg: 257-285.

Diekämper, J./Hümpel, A. (2015): Einleitung: Gentechnologien in Deutschland im Langzeit-Monitoring. In: Müller-Röber, B. et al. (Hrsg.): Dritter Gentechnologiebericht. Analyse einer Hochtechnologie. Nomos, Baden-Baden: 13-23.

Domasch, S./Boysen, M. (2007): Problemfelder im Spannungsfeld der Gendiagnostik. In: Schmidtke, J. et al. (Hrsg.): Gendiagnostik in Deutschland. Forum W, Dornburg: 179-188.

11 Der Wert für 2020 ist möglicherweise zu niedrig, da evtl. noch nicht alle Meldungen vorlagen. 
Fehse, B./Domasch, S. (Hrsg.) (2011): Gentherapie in Deutschland. Eine interdisziplinäre Bestandsaufnahme. Forum W, Dornburg.

Hucho, F. et al. (Hrsg.) (2008): Gentherapie in Deutschland. Eine interdisziplinäre Bestandsaufnahme. Forum W, Dornburg.

Köchy, K./Hümpel, A. (Hrsg.) (2012): Synthetische Biologie. Entwicklung einer neuen Ingenieurbiologie? Forum W, Dornburg.

Marx-Stölting, L. (2017): Einführung: Problemfelder und Indikatoren zur Epigenetik. In: Walter, J./ Hümpel, A. (Hrsg.): Epigenetik. Implikationen für die Lebenswissenschaften. Nomos, BadenBaden: 31-38.

Marx-Stölting, L./Könninger, S. (2018): Problemfelder der Gentechnologien gestern und heute. In: Hucho, F. et al. (Hrsg.): Vierter Gentechnologiebericht. Nomos, Baden-Baden: 279-297.

Müller-Röber, B. et al. (Hrsg.) (2007): Grüne Gentechnologie. Aktuelle Entwicklungen in Wissenschaft und Wirtschaft. 2. Aufl. Forum W, Limburg. (Problemfeldgrafik identisch zur 1. Auflage).

Müller-Röber, B. et al. (Hrsg.) (2009): Zweiter Gentechnologiebericht. Analyse einer Hochtechnologie in Deutschland. Forum W, Dornburg.

Müller-Röber, B. et al. (Hrsg.) (2013): Grüne Gentechnologie. Aktuelle wissenschaftliche, wirtschaftliche und gesellschaftliche Entwicklungen. 3. neubearb. u. ergänzte Aufl. Forum W, Dornburg.

Müller-Röber, B. et al. (Hrsg.) (2015): Dritter Gentechnologiebericht. Analyse einer Hochtechnologie. Nomos, Baden-Baden.

Osterheider, A. et al. (2019): Problemfelder und Indikatoren zum Thema Einzelzellanalyse. In: Walter, J./Schickl, H. (Hrsg.): Einzelzellanalyse in Forschung und Medizin. Eine Stellungnahme der interdisziplinären Arbeitsgruppe Gentechnologiebricht. Berlin: 66-76.

Osterheider, A. et al. (2020): Problemfelder und Indikatoren im Bereich der Organoidforschung. In: Bartfeld, S. et al. (Hrsg.): Organoide. Ihre Bedeutung für Forschung, Medizin und Gesellschaft. Nomos, Baden-Baden: 257-296.

Schmidtke, J. et al. (Hrsg.) (2007): Gendiagnostik in Deutschland. Status quo und Problemerkundung. Supplement zum Gentechnologiebericht. Forum W, Limburg.

Walter, J./Hümpel, A. (Hrsg.) (2017): Epigenetik. Implikationen für die Lebenswissenschaften. Nomos, Baden-Baden.

Wobus, A. et al. (Hrsg.) (2006): Stammzellforschung und Zelltherapie. Stand des Wissens und der Rahmenbedingungen in Deutschland. Supplement zum Gentechnologiebericht. Spektrum, München.

Zenke, M. et al. (Hrsg.) (2018): Stammzellforschung. Aktuelle wissenschaftliche und gesellschaftliche Entwicklungen. Nomos, Baden-Baden. 